\title{
Participation in heart failure home-care
}

Patients' and partners' perspectives

\author{
Lena Näsström
}

Division of Nursing Science

Department of Medical and Health Sciences

Linköping University, Sweden

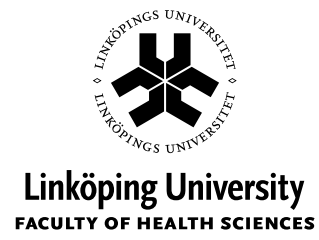

Linköping 2015 
@Lena Näsström 2015

Published articles have been reprinted with the permission of the copyright holder.

Printed in Sweden by LiU-Tryck, Linköping, Sweden, 2015

ISBN 978-91-7519-116-4

ISSN 0345-0082 
To my family

Mattias and Johan 



\section{CONTENTS}

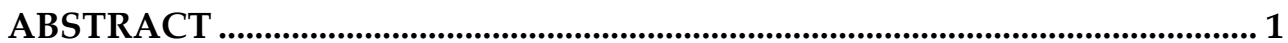

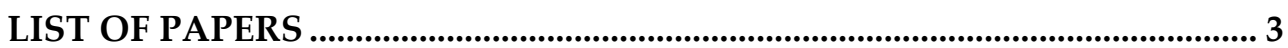

INTRODUCTION

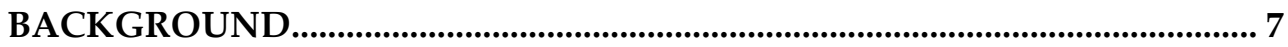

Living with heart failure................................................................................ 7

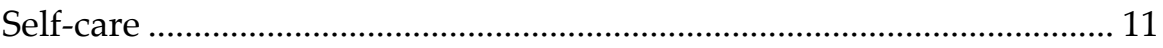

Heart failure home-care .......................................................................... 13

Conceptual stand points ........................................................................................ 14

Participation in care .......................................................................... 14

Rationale for this thesis .......................................................................... 18

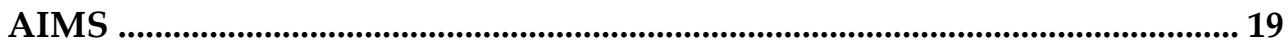

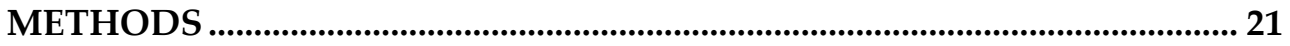

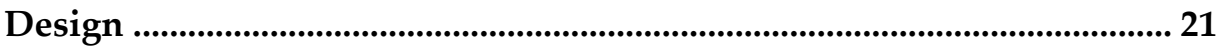

Sampling and participants .......................................................................... 22

Settings............................................................................................................. 25

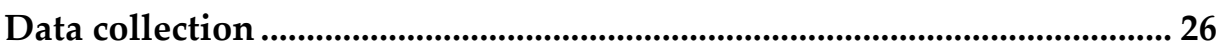

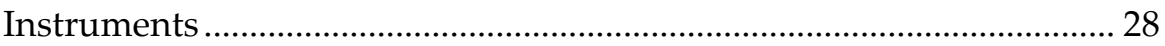

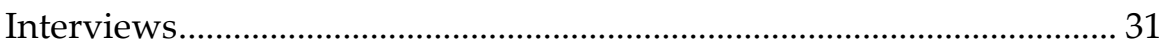

Video-recorded observations ............................................................... 32

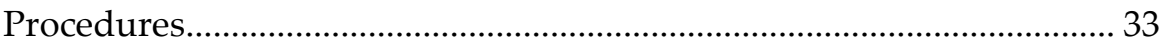

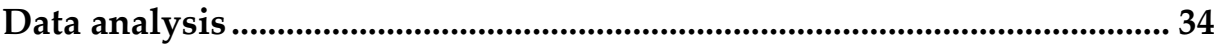

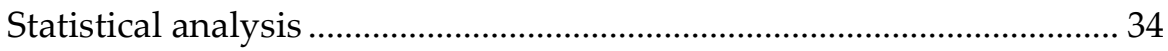

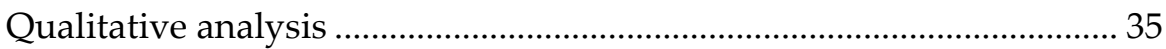

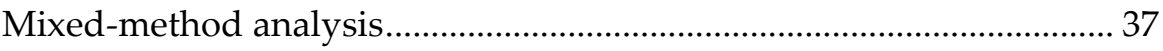

Ethical considerations .................................................................................... 37 


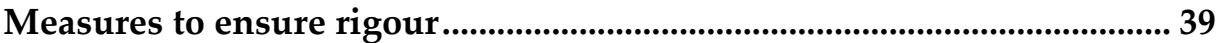

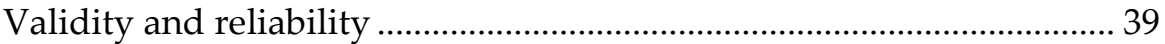

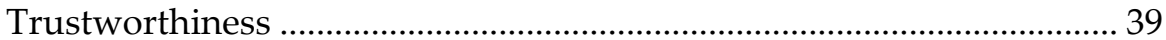

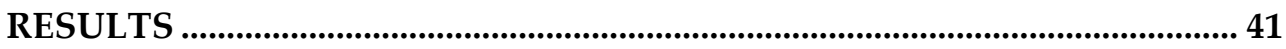

Factors associated with patient participation ................................................... 41

Influence on patient participation by heart failure home-care.................... 41

Patient participation in heart failure home-care.............................................. 43

Partners' experiences of participation............................................................ 46

Comprehensive description of participation in heart failure home-care 49

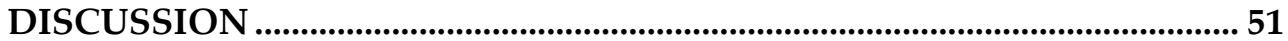

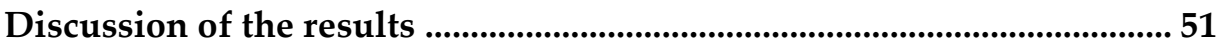

Factors associated with patient participation ........................................... 51

Patient participation in heart failure home-care ……………………....... 53

Partners' experiences of participation ....................................................... 56

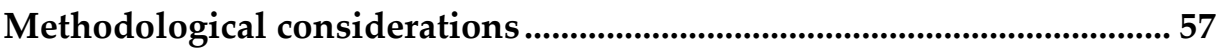

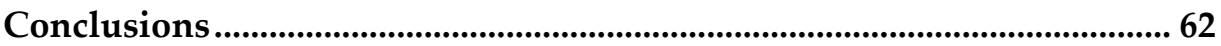

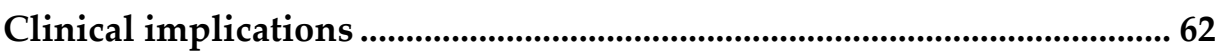

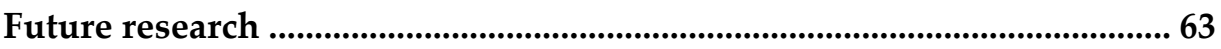

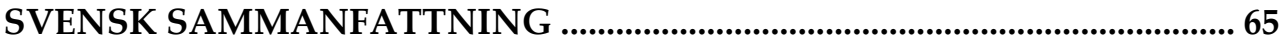

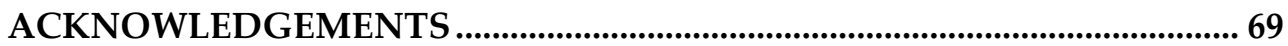

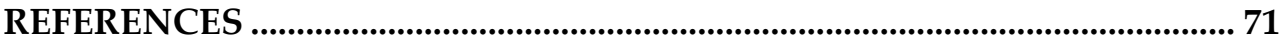




\section{ABSTRACT}

Introduction: Patient participation is important for improving outcomes and respecting self-determination and legal aspects in care. Heart failure is a chronic condition that puts high demands on self-care and patient participation. Patients often need advanced care due to deterioration of their heart failure symptoms, and one option is to provide care as home-care. There is limited knowledge of how patients with heart failure and their partners view participation in home-care.

Aim: The overall aim of this thesis was to describe different perspectives of participation in structured heart failure home-care among patients with heart failure and their partners.

Methods: All patients in this thesis received structured heart failure home-care, according to a model aiming to facilitate care, where safety, participation, and gaining knowledge about the illness and treatment, are in focus. Study I had a prospective pre-post longitudinal design including 100 patients with heart failure receiving home-care. Data was collected by self-administered questionnaires. Study II had a descriptive design. Nineteen patients receiving home-care were interviewed, and data was analysed using qualitative content analysis. Study III had a descriptive and explorative design. Data was collected by video-recorded observations of 19 home visits and analysed by qualitative content analysis. Study IV had a parallel convergent mixed-method design including 15 partners of patients receiving structured home-care. Data was collected by interviews and self-administered questionnaires. Datasets were first analysed separately and then together.

Results: Better self-care behaviour was significantly associated with all measured aspects of participation. Participation by received information increased significantly during the 12-month follow-up (I). Patients' descriptions of participation included communication between patients and health care professionals, access to care, active involvement in care, a trustful relation with health care professionals, and options for decision-making(II). Observed care encounters revealed that participation was made possible by; (i) interaction, including exchange of care-related information, care-related reasoning, and collaboration, (ii) an enabling approach, including the patient 
expresses own wishes and shows an active interest, and the nurse is committed and invites to a dialogue (III). Partners scored fairly positive for their participation in care and they performed different levels of caregiving tasks. Descriptions of participation included; adapting to the caring needs and illness trajectory, mastering caregiving demands, interacting with care providers, and gaining knowledge to comprehend the health situation. The mixed-method results showed both convergent results and expanded knowledge (IV).

Conclusions: Structured heart failure home-care facilitated participation both for patients and their partners. Patient participation with regard to received information improved significantly after receiving home-care. Aspects of patient participation were consistently associated with better self-care behaviour. Patients' and partners' descriptions revealed many aspects of participation, and observed home visits revealed how interaction and an enabling approach underpinned participation.

Keywords: Heart failure; home-care; involvement; mixed-method design; participation; partner; qualitative content analysis; self-care 


\section{LIST OF PAPERS}

This thesis is based on the following papers, which will be referred to in the text by their Roman numerals:

I. Näsström L, Jaarsma T, Idvall E, Årestedt K, Strömberg A. Patient participation in patients with heart failure receiving structured home care - a prospective longitudinal study. BMC Health Services Research 2014, 14:633.

II. Näsström LM, Idvall EA, Strömberg AE. Heart failure patients' descriptions of participation in structured home care. Health Expectations 2013. doi:10.1111/hex.12120. [Published ahead of print August 21, 2013].

III. Näsström L, Mårtensson J, Idvall E, Strömberg A. Participation in the Care Encounter among Patients with Heart Failure Receiving Homecare. In revision

IV. Näsström L, Luttik M.L, Idvall E, Strömberg A. Exploring partners' perspectives on participation in heart failure home-care. A mixed method design. Submitted 



\section{INTRODUCTION}

Participation is a goal in today's health care. Based on ideas of people's right for self-determination, many Western countries have focused on strengthening patient participation in care in the past few decades (WHO 1994, Tritter 2009, WHO 2013, Socialdepartementet 2014). The organisation of health care has been and is continuously undergoing changes, and care is now more often conducted at outpatient clinics or via home-care (Socialstyrelsen 2008, Genet et al. 2011, Socialstyrelsen 2014). Home-care is regarded as the preferred option by some care recipients, and as having potential for the individual to maintain independence (Tarricone \& Tsouros 2008).

Heart failure (HF) is a common health problem worldwide, and recent studies suggest a prevalence of $\sim 1-2 \%$ in the population (McMurray et al. 2012, Zarrinkoub et al. 2013, Go et al. 2014). In countries with an ageing population, the numbers of patients with HF are predicted to increase as HF drastically increases with older age (Mosterd \& Hoes 2007). The HF condition leads to typical signs and symptoms. The physical symptoms may be burdensome for the patients and lead to limitations in daily life and decreased health-related quality of life (HRQoL) (McMurray et al. 2012). Self-care plays a crucial role for patients with $\mathrm{HF}$, as patients have to maintain health promoting activities, monitor, and manage symptoms when deterioration occurs (Riegel \& Dickson 2008, Ponikowski et al. 2014). By engaging in self-care, patients actively participate in the management of their illness (Riegel et al. 2012). If the patient has a partner, the HF condition may influence that person's life situation in different ways (Luttik et al. 2005, 2009, Kang et al. 2011, Ågren et al. 2011).

The HF trajectory is unpredictable with a substantial risk for deterioration and increased need for health care (McMurray et al. 2012). Disease management programmes are common in HF care, and some include follow-up by home visits (Blue et al. 2001, Stewart et al. 2002, Morcillo et al. 2005, Patel et al. 2008, Stewart et al. 2012). Some programmes have shown positive effects on outcomes, such as increased survival (Stewart et al. 2002), and fewer readmissions (Blue et al. 2001, Stewart et al. 2002, Morcillo et al. 2005). No significant differences with regard to readmission and death were observed when comparing home-care versus clinic-based care (Stewart et al. 2012). 
Interventions to strengthen patient participation in care have been targeted in previous research and have shown positive outcomes (Greenfield et al. 1988, Arnetz et al. 2004, Loh et al. 2007). Being considered to have an active role in the care encounter and experiencing participation could be of importance for patients and/or their partners. However, there is limited research on participation in care among patients diagnosed with HF (Eldh et al. 2004, 2006b). No previous studies have been found that focus on participation among patients with HF and/or their partners within a home-care context.

Therefore, this thesis focuses on participation in care for patients diagnosed with HF and their partners when receiving HF home-care, in order to gain a better understanding of different perspectives for participation within this context. This type of knowledge can give important insights that can be used to improve care for both patients and their partners and improve satisfaction with care. 


\section{BACKGROUND}

\section{Living with heart failure}

\section{Definition, aetiology and epidemiology of heart failure}

Heart failure is a serious condition, defined clinically as a complex syndrome that includes typical symptoms and signs as a result of abnormality of the cardiac structure or function. These abnormalities lead to failure to pump enough blood and thereby failure to deliver sufficient levels of oxygen to the body's metabolising tissues (McMurray et al. 2012).

Heart failure may stem from a number of causes, where the different epidemiological and aetiological profiles affect progression and prognosis. Coronary artery disease and hypertension are the most common causes for HF (McMurray et al. 2012).

About 23 million people are living with HF worldwide (Bui et al. 2011). In Europe, the prevalence has been estimated to 15 million people (McMurray et al. 2012), and in the United States the estimated prevalence of HF is 5.1 million people (Go et al. 2014). In Sweden, the estimated prevalence of HF is $2.2 \%$ (Zarrinkoub et al. 2013). Prevalence of HF also increases in economically developing areas, for instance, parts of Latin America and Asia (Ponikowski et al. 2014). The magnitude of HF means a substantial need for health care, and in Europe and North America $1-3 \%$ of hospitalisations are due to HF (Cowie et al. 2014). As a result, the costs for care of these patients are high, accounting for $1-3 \%$ of health care expenditures in the western society (Bundkirchen \& Schwinger 2004, Neumann et al. 2009, Lloyd-Jones et al. 2010). Patients with $\mathrm{HF}$ are at risk of frequent hospitalisations, and the risk for readmission is high. However, due to more effective treatment there have been improvements as hospitalisations have decreased in recent years (McMurray et al. 2012, Dunlay \& Roger 2014). 


\section{Symptoms, disease severity and prognosis}

The most common symptoms of HF are shortness of breath, exercise intolerance, fatigue, and ankle swelling (McMurray et al. 2012). Heart failure leads to different levels of symptom severity, and the New York Heart Association functional classification (NYHA) is often used to describe them. The classification has four stages (I-IV), based on symptom severity and how limited patients are during physical activity (AHA 1994) (Table 1).

Table 1. Description of the New York Heart Association functional classification.

\begin{tabular}{cl}
\hline NYHA-class & Functional capacity \\
\hline I & $\begin{array}{l}\text { No limitation, ordinary physical exercise does not cause undue fatigue, } \\
\text { dyspnoea or palpitation }\end{array}$ \\
II & $\begin{array}{l}\text { Slight limitation of physical activity, comfortable at rest but ordinary } \\
\text { activities result in fatigue, dyspnoea or palpitations }\end{array}$ \\
III $\quad \begin{array}{l}\text { Marked limitation of physical activity, comfortable at rest but less than } \\
\text { ordinary activities result in fatigue, dyspnoea or palpitations }\end{array}$ \\
IV $\quad \begin{array}{l}\text { Unable to carry out any physical activity without discomfort, symptoms of } \\
\text { heart failure are present even at rest with increased discomfort with any } \\
\text { physical activity }\end{array}$
\end{tabular}

Heart failure diagnosis is associated with extensive HF morbidity as well as co-morbidity (Page \& Lindenfeld 2012). More than half of communitydwelling patients with HF, aged 80 and above, had five or more co-morbid conditions (Wong et al. 2011). Depressive symptoms are frequent among patients with HF. In a meta-analysis, Rutledge and colleagues reported that about $20 \%$ of patients diagnosed with HF meet the criteria for major depression (Rutledge et al. 2006). In more recent studies, one third of all patients with HF had depressive symptoms (Adams et al. 2012, Eastwood et al. 2012).

Mortality from HF has declined during the last few decades. However, the prognosis is still poor and the estimated five-year mortality is high, between $48-65 \%$ after initial diagnosis of HF (Dunlay \& Roger 2014). The HF prognosis is related to symptom severity, where deterioration in symptoms indicates an increased risk for hospitalisations and death (McMurray et al. 2012).

The burden of HF, including symptoms and consequences of these, together with the poor prognosis may affect both the patient and their family's life 
situation in many ways. Patients with HF therefore need to perform self-care in order to decrease symptoms, improve functional capacity, well-being, morbidity, and prognosis (Lainscak et al. 2011).

\section{Impact on everyday life and quality of life}

Symptoms such as shortness of breath and lack of energy or fatigue are frequently reported by patients with HF (Zambroski et al. 2005, Barnes et al. 2006a, Hertzog et al. 2010). Other common symptoms reported are dry mouth, drowsiness, and sleeping problems. Patients also experience psychological symptoms, e.g., difficulties to concentrate, or worrying (Zambroski et al. 2005). Symptoms have been shown to have an impact on patients' everyday life (Jeon et al. 2010, Falk et al. 2013), contributing to social isolation (Jeon et al. 2010). They are also experienced as burdensome (Barnes et al. 2006a). Depressive symptoms can delay patients from seeking help when deterioration occurs (Johansson et al. 2011), affect the patient's' ability to follow a medical regimen (Thomas et al. 2008), and increase the risk for poor self-care (Holzapfel et al. 2009). Depressive symptoms may also affect perceived control over symptoms, illness, and life (Eastwood et al. 2012), and influence health and the overall life situation (Dekker 2014).

Symptom burden, the HF condition and treatment, and the condition's impact on daily life contribute to a decreased quality of life (Jaarsma et al. 2010b). Patients with HF often report poor HRQoL (Juenger et al. 2002, Falk et al. 2013), often poorer than in other chronic conditions (Jaarsma et al. 2010b). Patients with HF have also reported poorer HRQoL compared to an agematched group of elderly people (Heo et al. 2007, Lesman-Leegte et al. 2009) and have consistently reported significantly lower in the area of physical health (Lesman-Leegte et al. 2009). Heart failure together with co-morbidity has an impact on HRQoL (Franzen-Årestedt et al. 2007), where progressing disease severity and increasing levels of co-morbidity are associated with poorer quality of life in patients with HF (Jaarsma et al. 2010b). Co-morbidities also influence the patient's self-care, where the presence of more than one illness has been shown to make it more complicated for the patients to manage their illness (Jeon et al. 2010).

Patients' descriptions reveal that receiving a HF diagnosis entails shaping a new identity (Welstand et al. 2009, Wingham et al. 2014). This process includes everything that results from the diagnosis, such as perceptions of day-to-day 
life, coping strategies, and making sense of an unpredictable life. Furthermore, the role of others, including health care professionals' influence, concept of self by explicit and implicit ability to reconstruct a new self, are also included in this process (Welstand et al. 2009). The process of shaping a new identity has different phases; disruption, sense making, reaction, and response. It ends with assimilation to the constraints and restrictions that are associated with daily life in HF. However, most of the patients need to revisit earlier phases due to deterioration of their HF (Wingham et al. 2014). These processes influence the patient's self-care (Welstand et al. 2009, Wingham et al. 2014).

\section{Family roles and perspective}

Between $45-70 \%$ of patients with HF have a partner or family member who is involved in their care (Buck et al. 2013). Suffering from a chronic condition, such as HF, often involves a number of symptoms and a need to adapt life to these (Jeon et al. 2010). This in turn may also affect the life situation for the patient's partner and family in many ways (Imes et al. 2011, Kang et al. 2011, Strömberg 2013), and family members are often involved as caregivers in different aspects of patient care (Welstand et al. 2009, Rosland et al. 2010). The circumstances resulting from the chronic illness may be challenging for the family's life situation, where family function, communication, and roles may change (Årestedt et al. 2014). Being a family member or partner of a person with HF means a risk of a negative impact on life situation and well-being (Kang et al. 2011, Whittingham et al. 2013). Caregivers may be both anxious and isolated (Kang et al. 2011). This negative impact could mean that partners' quality of life is affected when caring for a patient with HF (Luttik et al. 2005, 2009), thus influencing the caregivers' or partners' mental health (Ågren et al. 2011). Partners have reported a higher degree of symptoms of depression and anxiety compared to a healthy population (Chung et al. 2009). Caregiving has been associated with different levels of burden (Karmilovich 1994, Saunders 2008, Ågren et al. 2010).

However, family members may also have positive experiences of being involved in the care (Hogstel et al. 2005, Luttik et al. 2007, Kang et al. 2011, Whittingham et al. 2013). This positive experience may occur when it is possible to live life "here and now", appreciate the small things in life (Hogstel et al. 2005), and have each other (Gusdal et al. 2014). Improved relationships (Luttik et al. 2007, Kang et al. 2011), or reduced levels of stress when receiving support was perceived as positive (Kang et al. 2011). Better self-care 
maintenance in patients with HF has been associated with partners' perceived mental quality of life (Vellone et al. 2014), where shared care decisions have a strong relationship with better self-care maintenance (Sebern \& Riegel 2009).

\section{Self-care}

Health care professionals are expected to support the patient's self-care, which is also highlighted in the regulations that govern health care (Socialstyrelsen 2009). The patient becomes an active participant by engaging in self-care. Selfcare is considered essential in chronic illness and is defined as "a process of maintaining health through health promoting practices and managing illness" (Riegel et al. 2012 pg. 195). Riegel and co-workers' theory presumes that health is a dynamic and subjective process. The theory includes three key concepts; Self-care maintenance - behaviours to maintain physical and emotional stability, either self-determined or built on recommendation or agreement with health care professionals; Self-care monitoring - a process linking maintenance and self-care management by different monitoring activities. The goal is to recognise changes in health and respond to these before they become worse; Self-care management - evaluation of signs and symptoms and making decisions on how to handle the situation and also evaluate the effectiveness of the response (Figure 1). Underlying processes of self-care are decision-making, described as naturalistic decision-making, and reflection, which affects the ability to make sufficient self-care decisions (Riegel et al. 2012).

Practical recommendations for HF care state the importance of support for self-care (Lainscak et al. 2011). Self-care is fundamental to improve patient outcomes, as there is an association between the patient's ability to self-care and the management of various aspects of their condition (Evangelista \& Shinnick 2008, Riegel \& Dickson 2008, Lee et al. 2011). Patients need to make decisions about symptoms, lifestyle, and treatment options. Decisions are influenced by an interaction between personal characteristics, the problem, and environmental factors, where different aspects of decision- making are involved (Riegel et al. 2007). However, self-care is often inadequately performed and associated with difficulties. Coexisting co-morbidities may cause difficulties for the patient with HF to conduct adequate self-care. These patients are in need of self-care education that helps to integrate the forms of self-care required by the different conditions in their daily life (Dickson et al. 2013). 


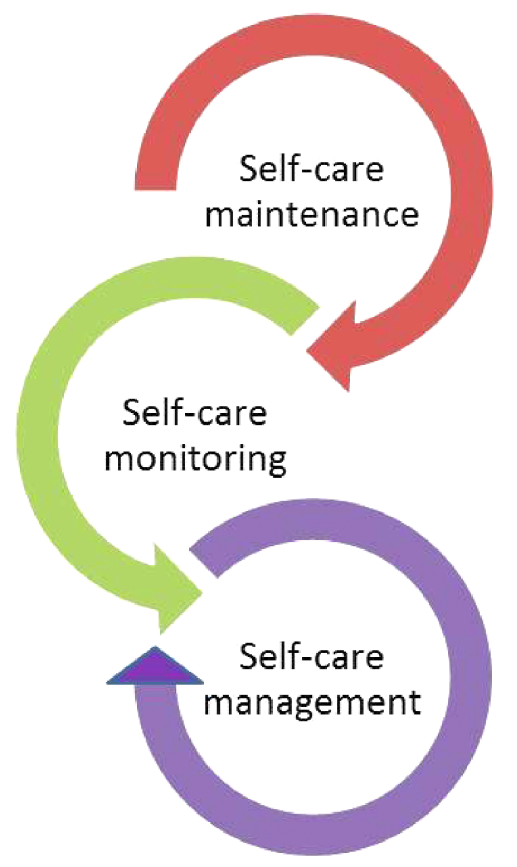

Figure 1. Key concepts in a middle-range theory of self-care in chronic illness (Riegel et al. 2012). Reprinted with permission.

In order to understand their HF and implement adequate self-care, patients need appropriate education. Studies show that there is a discrepancy between obtaining and remembering information about HF (Strömberg 2005). There are gaps in patients' knowledge and understanding of HF self-care. A key skill is to be able to integrate self-care recommendations in normal life to promote effective self-care. In addition, early symptom detection, recognition, and taking action are important for effective management (Clark et al. 2014). Although patients' knowledge has been shown to increase after interventions with education, outcomes are not always improved, which shows the complexity of HF self-care (Boyde et al. 2011).

Relationships with family and friends improve adherence to healthy behaviours and self-care confidence (Sebern \& Riegel 2009). Patients living alone without a family are therefore particularly vulnerable and need special attention with regard to self-care (Dunbar et al. 2008). 


\section{Heart failure home-care}

A previous overview of home-care in Sweden showed that it was increasing, and patients with HF could be a potential target group for this form of care (Socialstyrelsen 2008). Structured follow-up for patients with HF in home-care has been found to be effective by reducing both mortality and rehospitalisations (McAlister et al. 2004). Structured home- care has decreased the number of re-admissions significantly (Blue et al. 2001, Stewart et al. 2002), increased survival (Stewart et al. 2002), and thereby inflicting lower medical costs for home-care compared to traditional health care (Patel et al. 2008). However, the organisation of HF management differs between European countries (Seferovic' et al. 2013). Specialised HF home-care has not been implemented for the majority of patients, including Sweden (Jaarsma et al. 2006). Succeeding with the transition from hospital care to home-care is crucial for patients with HF. Home visits can provide an opportunity to obtain a more complete picture of the HF patient's situation, including their ability to manage their illness at home (Jaarsma \& Luttik 2011). The home environment may provide better conditions for patient education, as the patient may be less anxious and more open to learning (Yu et al. 2006). From a patient perspective, home-care may be important in order to avoid hospital admissions and have an opportunity to live a more independent life (Whitty et al. 2012).

A European home-care model for HF patients, The Heart Failure at Home Model, has been developed (Jaarsma et al. 2010a). The model was developed through a literature review aiming to identify existing components in home-care programmes, and through a survey of 100 heart failure management programmes in Europe. Based on these, criteria for optimal home-care were formulated for patients with HF. These criteria were examined by practitioners and an expert group of scientists in the field. The Heart Failure at Home Model consists of six components for home-based management of patients with HF, the components are displayed in Table 2.

The model aims to facilitate care for the patient and values such as safety, participation, and having knowledge about illness and treatment are in focus. The feasibility of The Heart Failure at Home Model has been tested in the Netherlands and Sweden, but this thesis only focuses on the Swedish part of the project. 
Table 2. Description of components in The Heart Failure at Home Model (Jaarsma et al 2010a).

\begin{tabular}{ll}
\hline Components & Summary of content \\
\hline A multi-disciplinary team & $\begin{array}{l}\text { Patient-centred collaborative care between care providers and } \\
\text { patient/family. Minimum physicians and nurses, if possible other care } \\
\text { professions on a regular or consultative basis. }\end{array}$ \\
$\begin{array}{l}\text { Competency-based staff } \\
\text { education }\end{array}$ & $\begin{array}{l}\text { Education to increase knowledge and skills on HF care in team } \\
\text { members, e.g., nurses learnt about parts of the "European curriculum } \\
\text { for clinical expertise in heart failure". Knowledge and skills to treat the } \\
\text { patient as a whole. Team-based educational activities. }\end{array}$ \\
$\begin{array}{l}\text { Joint care plans and/or } \\
\text { care paths }\end{array}$ & $\begin{array}{l}\text { Care is planned in collaboration between patient/family and the care } \\
\text { team. Possibility to triage patients to different care pathways related } \\
\text { to illness trajectory. } \\
\text { Care goals that can be targeted and evaluated. Follow-up symptoms } \\
\text { and outcomes by standardized instruments and structured } \\
\text { documentation. }\end{array}$ \\
$\begin{array}{l}\text { Optimized treatment } \\
\text { according to guidelines }\end{array}$ & $\begin{array}{l}\text { Ongoing assessment of pharmacological and non-pharmacological } \\
\text { treatment. Drug titration to highest tolerable dose of HF drugs. }\end{array}$ \\
$\begin{array}{l}\text { Follow-up on self-care management with special emphasis on } \\
\text { symptom recognition and adherence to treatment. Options for }\end{array}$ \\
advanced treatment. Options for palliation or end-of-life care.
\end{tabular}

\section{Conceptual standpoints}

\section{Participation in care}

The foundation for health care should be based on respect for a person's selfdetermination and integrity (Socialdepartementet 1982, WHO 1994). Respect for the person, the individual's right to self-determination with mutual respect and understanding of each other is the basis for person-centred care, where the result aims to lead to well-being, satisfaction and participation in care (McCormack \& McCance 2006). Patient participation has been focused upon both nationally and internationally during the last few decades, and efforts 
have been made to enhance patient participation in care (WHO 1994, Moumjid et al. 2011, Tritter 2011, Socialstyrelsen 2012). In Sweden, patient participation has recently been further enhanced by a new Patient Act. This act aims to strengthen the patient's position in care and thereby promote selfdetermination, integrity, and participation (Socialdepartementet 2014).

Participation in care is believed to have benefits such as better treatment results and increased satisfaction with care (Ashworth et al. 1992, Sahlsten et al. 2008). Interventions aiming to increase patient participation have shown significant improvements on outcomes with regard to adherence to treatment in depression (Loh et al. 2007), physical activity (Arnetz et al. 2004), and diabetes control (Greenfield et al. 1988).

\section{The concept participation}

The concept participation is frequently used in the health care context, and in legal texts it is often referred to as taking part in decisions and receiving information (Eldh et al. 2010). A broader definition is offered by The International Classification of Functioning, Disability and Health (ICF), that defines participation as "involvement in a life situation". This includes a dynamic interaction between the health condition, body functions and structures, participation and activity, and contextual factors (WHO $2001 \mathrm{pg}$. 10). The concept patient participation can be seen as reflecting both a philosophical approach to patient care as well as a practical approach to care (Jewell 1996). Within the health care context, patient participation builds on an assumption that patients both want and benefit from taking an active role in their care (Cahill 1998). The concept patient participation is multifaceted (Cahill 1996, 1998, Sahlsten et al. 2008, Lyttle \& Ryan 2010). Two subsequent concept analyses have identified mainly the same attributes that define patient participation; an existing established relationship, a will to move power and control to the patient, shared information and knowledge between the patient and the health care providers, and active mutual engagement in intellectual and/or physical activity during the nursing process (Cahill 1996, Sahlsten et al. 2008). A benefit should be associated with intellectual and/or physical activity (Cahill 1996). The later concept analysis (Sahlsten et al. 2008) provided more details as to what constitutes the different attributes. Mutual engagement should also be evident throughout the whole nursing process. 
Other concepts are closely related to participation and often used interchangeably, e.g., partnership, involvement, and collaboration. These concepts could also be described as distinct concepts in a hierarchical structure. Involvement and collaboration forms the base and are precursors to participation which in turn is the precursor to partnership, which is situated at the top of this hierarchical structure (Cahill 1996).

However, with regard to the use of the concepts in the research literature, participation and involvement are used synonymously in this thesis.

\section{Patients' view of participation}

Patients' experiences of participation have been studied within different care contexts, revealing different aspects included in participation. Participation includes interaction with health care providers (Bastiaens et al. 2007, Larsson et al. 2007, Eldh et al. 2010), exchange of information (Eldh et al. 2006a, Bastiaens et al. 2007, Larsson et al. 2007, Höglund et al. 2010, Larsson et al. 2011b), and being able to understand the information (Eldh et al. 2010). Participation means to achieve knowledge, including good conditions for communication (Larsson et al. 2007, Eldh et al. 2010). Furthermore, being treated with respect is also described as participation (Bastiaens et al. 2007, Larsson et al. 2007, Eldh et al. 2010, Larsson et al. 2011b). Patients have referred to decision-making in relation to participation, but their preferences for involvement in decisions vary (Guadgnoli \& Ward 1998, Saino et al. 2001, Say et al. 2006, Bastiaens et al. 2007, Thompson 2007, Ekdahl et al. 2010, 2011). Taking an active role in decision-making could mean that patients both want to receive information about care or treatment options, but also be involved in decisions when there are more than one possible alternative (Guadgnoli \& Ward 1998, Saino et al. 2001, Larsson et al. 2007). Other findings have shown that some patients entrust themselves to the health care system, stating that they prefer a passive role and do not want to participate in decision- making (Ekdahl et al. 2010). Patients with HF receiving care from an HF outpatient clinic have also pointed out comprehending and being confident, seeking and maintaining a sense of control (Eldh et al. 2004), being responsible and accepting this responsibility (Eldh et al. 2006b) as participation. 


\section{Families' view of participation in care}

Previous knowledge about how partners of patients with HF view the concept participation is more limited. Partners of patients with HF have described involvement as a positive experience when being involved with others and included in the care of the patient. Being kept at a distance, lacking social support, or being socially isolated were negative experiences (Mårtensson et al. 2001). Informal caregivers wished to be invited to share their knowledge with health care providers but instead they often experienced a struggle with regard to their contact with health care professionals. On the other hand, when they expressed their right to be present during meetings, this was often positively received by care providers (Gusdal et al. 2014). Partners and family often act as informal caregivers and participate in care (Aldred et al. 2005, Clark et al. 2008, Rosland et al. 2010, Pimajariyakul et al. 2012). They can be involved both through direct and indirect activities, e.g., in connection with patient self-care or contacts with care providers (Buck et al. 2015). Involvement also includes practical support, physical care, and emotional support (Aldered et al. 2005, Kang et al. 2011). Family participation has been described to include participation in physical care, in decision-making, or in the evaluation of care (Lee \& Craft-Rosenberg 2002).

\section{Health care professionals' view of patient participation}

Arnetz and co-workers theorised that staff behaviour and attitudes, together with the patient's behaviour and attitudes constitute patient involvement, and this was affected by the care environment. Patient involvement was supposed to have a positive effect on patient outcomes, which in turn lead back to patient and staff attitudes and behaviour (Arnetz et al. 2008c). Health care professionals viewed patient participation as both important and valuable (Eldh et al. 2006b, Arnetz et al. 2008b, Höglund et al. 2010). Nurses' perspective of participation included an interactional process by mutuality and negotiation based on interpersonal procedures, a therapeutic approach, focus on resources, and opportunities for influence (Sahlsten et al. 2007). Strategies to achieve participation were close cooperation, getting to know the person and reinforcing self-care capacity (Sahlsten et al. 2009). A more passive description of patient participation was given by nurses in a HF out-patient clinic. They viewed participation as something they gave the patient, and they felt that they activated the patient. Furthermore, non-participation was due to patients not accepting what they were offered (Eldh et al. 2006b). Information 
exchange was given a prominent role in patient participation (Eldh et al. 2006b, Höglund et al. 2010). There could be barriers for participation, especially during more acute phases of illness or due to personal, cultural, or social factors (Höglund et al. 2010). Other factors that could obstruct participation were lack of insight or knowledge among nurses, a paternalistic attitude in the family, and a number of barriers in the organisation of care (Sahlsten et al. 2005).

\section{Rationale for this thesis}

Respecting a person's right for self-determination is a fundamental value that has been focused upon for several decades, and patient participation has been addressed in health care, legislation, and policy documents. Earlier research on the concept of participation points out that the expressions of how participation is experienced are multifaceted. We also know from earlier research that participation may be of importance for outcomes of care. There is limited knowledge of how patients with HF view participation in general, and this knowledge is even sparser in a home-care context. This thesis aims to increase knowledge about how patients with HF in a home-care context view and experience their participation and how patient participation is expressed during home-care encounters. Furthermore, there is a need for further knowledge about possible factors related to patient participation and if participation changes over time in a specific care context, such as home-care. Patients with HF live their lives in a social context. There is a growing body of knowledge about partners' important role for outcomes in chronic illness, and their substantial contribution to patient care. However, there is limited knowledge of how partners of patients with HF receiving home care view participation. Therefore, this thesis also aims to gain a better understanding of partners' perspectives of participation. These different perspectives may be of importance for improving care and satisfaction with care, both for patients and their partners, which in turn can help improve health outcomes. 


\section{AIMS}

The overall aim of this thesis was to describe different perspectives of participation in structured heart failure home-care among patients with heart failure and their partners.

The specific aims were:

To describe the influence of structured home-care on patient participation over time in patients diagnosed with heart failure, and to explore factors associated with participation in care (Study I)

To examine how patients with heart failure who receive structured home care describe participation in the care (Study II)

To identify and describe participation in care encounters during home visits in structured heart failure home-care (Study III)

To gain a better understanding of the partners' perspectives on participation in the care for patients with heart failure receiving structured home-care, and to describe aspects of participation, performing caregiving tasks, quality of life, and symptoms of depression in partners, and explore the relationship between these variables (Study IV) 



\section{METHODS}

\section{Design}

This thesis is based on four studies using different methods for data collection and analysis to describe people's experiences of participation. By combining different modes of inquiry and using integrative strategies, knowledge needs in nursing could be met (Hagedorn \& Zahourek 2007). This combination of methods could be described as triangulation and be one way of strengthening the study design when studying a research problem or phenomenon (Patton 2002).

Data was collected systematically by questionnaires in a pre-post longitudinal design, in order to describe and explore participation in a group of patients with HF receiving structured home-care (I). To explore and/or describe different perspectives of patient participation, a qualitative approach was applied with data collected through interviews (II) and observations (III). A mixed-method approach was used to gain a better understanding of participation among partners of patients with HF. Systematically collected data from questionnaires in combination with qualitative data from interviews was used (IV). An overview of the designs and methods' are shown in Table 3. 
Table 3. Overview of designs and methods study I-IV.

\begin{tabular}{|c|c|c|c|c|}
\hline & Study I & Study II & Study III & Study IV \\
\hline Design & $\begin{array}{l}\text { Prospective } \\
\text { pre-post longitudinal }\end{array}$ & Descriptive & $\begin{array}{l}\text { Explorative, } \\
\text { descriptive }\end{array}$ & Mixed-method \\
\hline Inclusion criteria & $\begin{array}{l}\text { Patients }>18 \text { years } \\
\text { diagnosed with heart } \\
\text { failure }\end{array}$ & $\begin{array}{l}\text { Quota sample of } \\
\text { participants from } \\
\text { study I }\end{array}$ & $\begin{array}{l}\text { Purposeful sample of } \\
\text { participants from } \\
\text { study I }\end{array}$ & $\begin{array}{l}\text { Purposeful sample } \\
\text { partners to patients } \\
\text { from study I }\end{array}$ \\
\hline Participants & 100 patients & 19 patients & $\begin{array}{l}17 \text { patients* } \\
10 \text { nurses }\end{array}$ & 15 partners \\
\hline Data collection & $\begin{array}{l}\text { Questionnaire: } \\
\text { Demographic and } \\
\text { clinical characteristics } \\
\text { Participation } \\
\text { Self-care behaviour } \\
\text { Knowledge } \\
\text { Symptoms of } \\
\text { depression }\end{array}$ & Individual interviews & $\begin{array}{l}\text { Video-recorded } \\
\text { observations }\end{array}$ & $\begin{array}{l}\text { Questionnaire: } \\
\text { Demographic data } \\
\text { Participation } \\
\text { Symptoms of } \\
\text { depression } \\
\text { HRQoL } \\
\text { Performed caregiving } \\
\text { tasks** }\end{array}$ \\
\hline Time data collection & $\begin{array}{l}\text { Baseline, 1, } 6 \text { and } \\
\text { 12-months }\end{array}$ & $\begin{array}{l}\text { 14-162 days after } \\
\text { inclusion }\end{array}$ & $\begin{array}{l}\text { 10-140 days } \\
\text { after inclusion }\end{array}$ & $\begin{array}{l}\text { Questionnaire } \\
\text { baseline and } 6 \\
\text { months } \\
\text { Interviews } 1 \text { week to } \\
6 \text { months after } \\
\text { inclusion }\end{array}$ \\
\hline Data analysis & $\begin{array}{l}\text { Descriptive statistics } \\
\text { Repeated measure } \\
\text { ANOVA } \\
\text { Spearman's rho } \\
\text { Multiple linear } \\
\text { regression }\end{array}$ & $\begin{array}{l}\text { Qualitative content } \\
\text { analysis, manifest and } \\
\text { latent }\end{array}$ & $\begin{array}{l}\text { Qualitative content } \\
\text { analysis, manifest and } \\
\text { latent }\end{array}$ & $\begin{array}{l}\text { Descriptive statistics } \\
\text { Spearman's rho } \\
\text { Wilcoxson signed } \\
\text { rank test } \\
\text { Qualitative content } \\
\text { analysis, manifest and } \\
\text { latent }\end{array}$ \\
\hline
\end{tabular}

* In total 19 video-recorded observations, home visits for two men were observed twice.

** Performed caregiving tasks were measured once, at 6 months

$\mathrm{HRQ}$ oL= health related quality of life

\section{Sampling and participants}

All eligible patients at four home-care units were assessed for study participation from February 2010 to October 2011(I). Patients' cohabitant family (IV) were included during the same period. A flowchart of the inclusion of patients (I-III) and cohabitant family (IV) is presented in Figure 2. 
To describe and explore participation, data was collected in a consecutive sample of 100 patients diagnosed with HF receiving structured home-care from one of four different home-care units (I). Inclusion criteria were 18 years or older, and diagnosed with HF as defined by The European Society of Cardiology (McMurray et al. 2012). Exclusion criteria were expected survival less than three months, cognitive impairment or mental illness that could affect informed consent or active participation, and difficulties to speak or understand Swedish. Mean age was 82 years $( \pm 8.8)$ and more than half of the 100 participants were men (Table 4). The majority of the patients were classified in NYHA III, and had quite a high prevalence of co-morbid

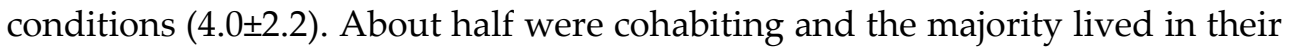
own house or flat.

From the group of 100 patients, a quota sample of nineteen patients was selected for an interview (II). This sample was made to ensure that the included patients reflected the group of patients with HF receiving home-care from the four home-care units. Among those patients the majority were men, age ranging between 63 and 90 years (mean 77, median 80). Their need for home-care ranged between receiving home visits twice a day to once a month.

A purposeful sampling was selected for inclusion of patients to the observations of home-care encounters (III). This sample was made to ensure variation with regard to severity of the HF condition, need for care, age, and gender. Seventeen patients were included, age ranging between 63 and 93 years (mean 77, median 80 ). The majority of the patients were in NYHA III and their need for home-care also ranged between receiving home visits twice a day to once a month. About half of the patients were cohabiting. The age of the ten participating nurses ranged between 26 and 62 years (mean 40, median 40).

The 100 patients' cohabitant families were invited to participate (IV). Inclusion criteria were 18 years or older and being cohabitant family of a patient included in study I. Exclusion criteria were cognitive impairment or mental illness that could affect informed consent or active participation, and difficulties to speak or understand Swedish. From the eligible 39 cohabitant families, a purposeful sampling was selected, aiming to include partners with a variation in age, gender, and patient care needs. Fifteen partners were selected, age ranging between 52 and 92 years (median 77). About two thirds were women. Eight partners reported no morbidity conditions, and the other 
seven reported between one and three conditions. The most prominent condition was rheumatoid arthritis/SLE. Two partners were working and the rest were retired.
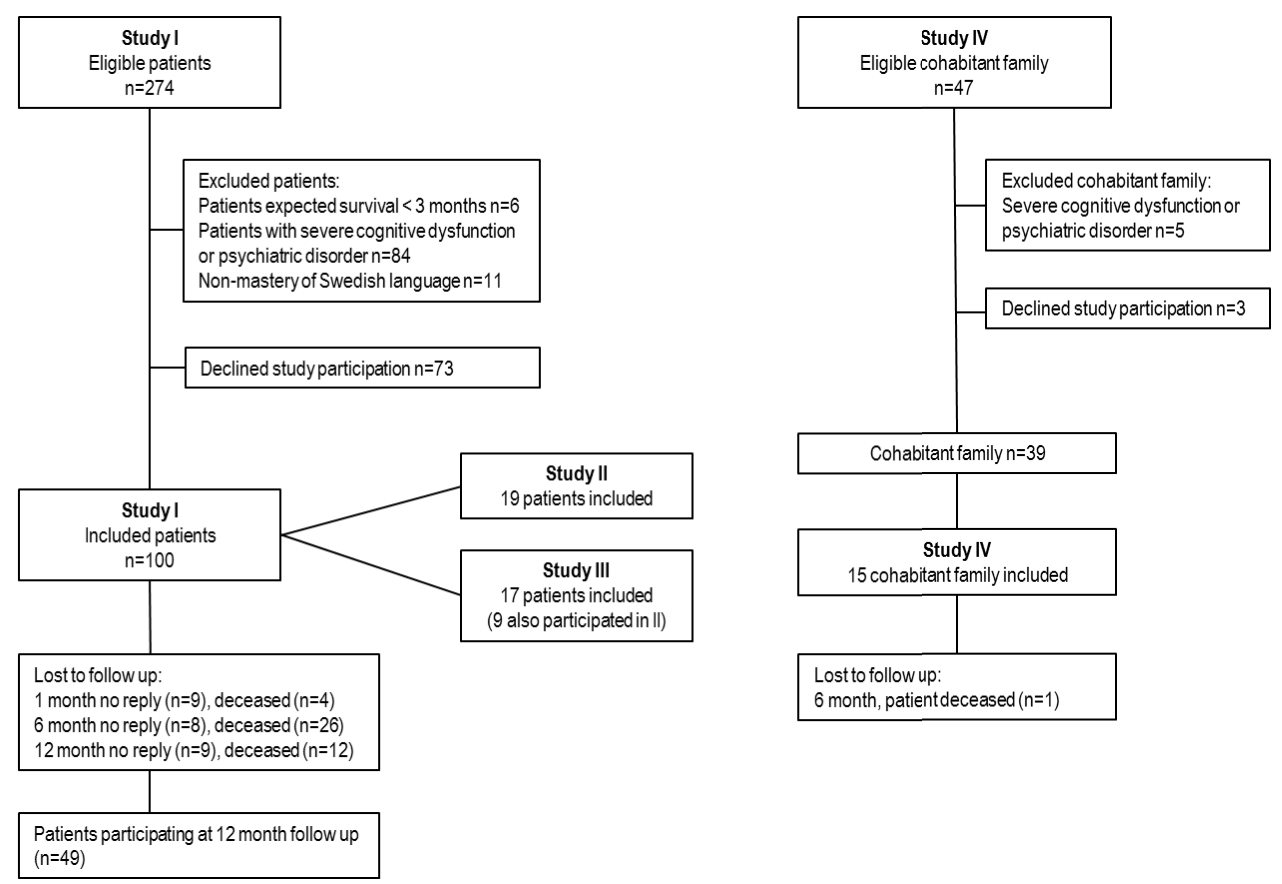

Figure 2. Flow chart illustrating included participants study I-IV and follow-up (I, IV) 
Table 4. Demographic and clinical characteristics for participants (I-IV).

\begin{tabular}{|c|c|c|c|c|}
\hline $\begin{array}{l}\text { Demographic and } \\
\text { clinical characteristics }\end{array}$ & $\begin{array}{l}\text { Study I } \\
(\mathrm{n}=100)\end{array}$ & $\begin{array}{l}\text { Study II } \\
(n=19)\end{array}$ & $\begin{array}{l}\text { Study III } \\
(\mathrm{n}=17)\end{array}$ & $\begin{array}{l}\text { Study IV } \\
(\mathrm{n}=15)\end{array}$ \\
\hline Age mean (SD) & $81.7(8.8)$ & 77 & 77 & \\
\hline median $(\mathrm{Q} 1 ; \mathrm{Q} 3)$ & & & & $77(73 ; 84)$ \\
\hline Men n & 62 & 13 & 11 & 4 \\
\hline Cohabitation $n$ & 52 & 8 & 8 & 15 \\
\hline \multicolumn{5}{|l|}{ Housing n } \\
\hline Apartment & 80 & & & \\
\hline Own house & 17 & & & \\
\hline Block of service flats & 3 & & & \\
\hline Home-help service $n$ & 46 & & & \\
\hline \multicolumn{5}{|l|}{ Education level n } \\
\hline $\begin{array}{l}\text { Elementary, primary and secondary } \\
\text { school }\end{array}$ & 67 & & & 8 \\
\hline High/trade school 2 years & 5 & & & 2 \\
\hline High-school 3-4 years & 10 & & & 4 \\
\hline Higher education/university & 18 & & & 1 \\
\hline \multicolumn{5}{|l|}{ NYHA class $n$} \\
\hline$\|$ & 12 & & 1 & $2^{*}$ \\
\hline III & 80 & 18 & 16 & $12^{*}$ \\
\hline IV & 8 & 1 & & $1^{*}$ \\
\hline $\mathrm{CCl}$ mean (SD) & $4.0(2.2)$ & & & \\
\hline \multicolumn{5}{|l|}{ Medication $n$} \\
\hline ACEI/ARB & 72 & & & \\
\hline$\beta$-blockers & 87 & & & \\
\hline MRA & 49 & & & \\
\hline Diuretics & 95 & & & \\
\hline
\end{tabular}

Key for abbreviations: NYHA class = New York Heart Association Functional

Classification, $\mathrm{CCl}=$ Charlson Co-morbidity Index, $\mathrm{ACEI}=$ Angiotensin-Converting

Enzyme Inhibitors, $A R B=$ Angiotensin Receptor Blocker, $\beta$-blockers $=$ Beta blockers,

$\mathrm{MRA}=$ mineralocorticoid receptor antagonists

*The patients NYHA-classification

\section{Settings}

The organisation of home-care in Sweden differs between regions and in level of care. All patients were enrolled to receive care at home from one of four home-care units, according to their HF diagnosis. Two of the four units were situated in a medium sized Swedish city (about 145000 inhabitants). One unit provided advanced home-care organised by the hospital, with 24 hours access to care and a back-up ward. The other unit was organised within primary care during the day, but with access to back-up by a primary home-care team 
around the clock, seven days a week. The other two units were situated in a metropolitan city in Sweden. These two units provided advanced home-care organised in a hospital setting, with 24 hours access to care and a back-up ward.

All units had a minimum of nurses and physicians specialised in general care in the care team. Access to care by other care professionals, e.g., physiotherapists, occupational therapists, or counsellors/social workers, could be provided to all patients if needed. The organisation of these other professionals, i.e., whether they were organised at the home-care unit or if they were consulted, differed between the units. The organisation of patient care at each unit was determined by the patient's health status. The number of home visits for each patient therefore varied. Some patients were discharged and received follow-up in primary care or at out-patient clinics when their health status had stabilised. Other patients remained enrolled to the home-care unit. Patients discharged from home-care could be re-admitted to the homecare unit if needed.

\section{Data collection}

In this thesis, different methods for data collection were used to capture different perspectives of participation from patients with HF and their partners. Collection of quantitative data (I, IV) was made by self-administered questionnaires, including validated instruments and background variables. Data about patient co-morbidities, socio-demographic and clinical characteristics was collected from medical records (I). Data of partners' morbidity was collected by structured interviews (IV). An overview of the instruments is displayed in Table 5. Qualitative data collection by interviews (II, IV) and video-recorded observations (III) was also performed. 
Table 5. Overview instruments (I, IV).

\begin{tabular}{|c|c|c|c|c|}
\hline Scales/ Indices & $\begin{array}{l}\text { Number of } \\
\text { items }\end{array}$ & Total score & $\begin{array}{l}\text { Internal } \\
\text { consistency } \\
\text { reported by } \\
\text { instrument } \\
\text { developer * }\end{array}$ & $\begin{array}{l}\text { Internal } \\
\text { consistency } \\
\text { in this study } \\
\text { * }\end{array}$ \\
\hline \multicolumn{5}{|l|}{ Patients' view of participation (I) } \\
\hline Patient involvement & 6 & $6-24$ & 0.82 & 0.80 \\
\hline Information & 5 & $5-20$ & 0.87 & 0.84 \\
\hline Patient needs & 7 & $7-28$ & 0.82 & 0.88 \\
\hline Overall satisfaction involvement in care & 1 & $1-10$ & & \\
\hline \multicolumn{5}{|c|}{$\begin{array}{l}\text { Relatives' view of participation, information } \\
\text { and contact (IV) }\end{array}$} \\
\hline Participation & 3 & 3-12 & $0.73-0.80$ & 0.90 \\
\hline Information & 4 & $4-16$ & $0.73-0.86$ & 0.91 \\
\hline Contact & 3 & 3-12 & $0.76-0.83$ & 0.82 \\
\hline $\begin{array}{l}\text { Self-care behaviour (I) } \\
\text { (EHFScB-9) }\end{array}$ & 9 & $9-45$ & 0.80 & 0.72 \\
\hline Heart failure knowledge (I) & 15 & $0-15$ & 0.62 & 0.54()$^{* *}$ \\
\hline $\begin{array}{l}\text { Symptoms of depression (I, IV) } \\
\text { (PHQ-9) }\end{array}$ & 9 & $0-27$ & $0.86-0.89$ & $\begin{array}{l}0.80(\mathrm{I}) \\
0.84(\mathrm{IV})\end{array}$ \\
\hline \multicolumn{5}{|l|}{ Health related quality of life (IV) } \\
\hline EQ-index & 5 & $-0.59-1.0$ & - & - \\
\hline EQ-VAS & 1 & $0-100$ & & \\
\hline $\begin{array}{l}\text { Performing caregiving tasks (IV) } \\
\text { (DOBI) }\end{array}$ & & & $0.81-0.84$ & \\
\hline Personal care & 11 & $1-3$ & & 0.83 \\
\hline Motivational support & 10 & $1-3$ & & 0.87 \\
\hline Emotional support & 6 & $1-3$ & & 0.86 \\
\hline Practical and treatment related support & 11 & $1-3$ & & 0.91 \\
\hline
\end{tabular}

*Cronbach's a coefficients

** Kuder-Richardson reliability coefficients (KR-20) 


\section{Instruments}

\section{Participation}

A Swedish questionnaire developed by Arnetz and co-workers, assessing involvement in care among patients hospitalised due to myocardial infarction was used (Arnetz et al. 2008a) (I). The instrument includes six scales and one single item. In collaboration with the instrument developer, three of the scales and the single item were selected for measuring aspects of participation in this study. The three other scales are about the acute illness experience, plans for care and rehabilitation and activity after discharge, and were therefore not relevant to this study (I). To adapt the instrument to patients with HF in a home-care context, the wording of two items was slightly changed. One item was adjusted from Did you have the opportunity to ask questions when you were being discharged to Did you have the opportunity to ask questions during conversations. The second item was changed from Did you receive the information you wanted about: what occurred during the acute phase to what occurred if the HF deteriorated. The three scales used were Patient involvement (6 items), measuring the patients' definition of involvement or what it meant to them, Information (5 items) measuring to what degree the patients' received information and explanations about the condition and treatment, Patient needs (7 items) measuring to what degree the patients' felt that needs were fulfilled with regard to asking questions, understanding given information and being treated with respect. The one single item was Overall satisfaction with involvement in care. In the three scales, the patients were asked to rate a statement on a four-point Likert-type scale, ranging from don't agree at all (1) to agree completely (4), or no, not at all (1) to yes, to a great degree (4). For the single item, the patients were asked to rate their overall satisfaction with involvement in care on a numeric rating scale from not at all satisfied (1) to very satisfied (10). For all scales and the single item, higher scores indicate a more positive rating. The total scores for the scales and single item are 6-24 (Patient involvement), 5-20 (Information), 7-28 (Patient needs) and 1-10 (Overall satisfaction with involvement in care). The three scales have previously demonstrated good validity and reliability (Arnetz et al. 2008a).

A Swedish questionnaire developed to measure how patients' relatives perceive the quality of geriatric care was used (Verho \& Arnetz 2003) (IV). The 
instrument includes eight quality indices, grouped in three dimensions. In collaboration with the instrument developer, ten items (included in three of eight indices) were selected for measuring the partners' aspects of participation in a HF home-care context. To adapt the instrument for partners of patients with HF in a home-care context, the wording of one item was slightly changed. This meant that one word was adjusted from rehabilitation to care. The three indices were; Participation (3 items), Information (4 items), and Contact ( 3 items). Furthermore, two single questions from the questionnaire were used; if they participated in the patient's care to the extent they wanted and if they experienced too high demands on themselves in the care of the patient. Each item was scored on a four-point Likert-type scale, ranging from no, not at all (1) to yes, to a great degree (4). Finally, one question was added, where the partner was asked to score their overall satisfaction with participation in the care of their loved one. This item was scored from 1 (not at all satisfied) to 10 (very satisfied). The total scores for the indices are 3-12 (Participation), 4-16 (Information) and 3-12 (Contact). The three indices have previously demonstrated good validity and reliability (Verho \& Arnetz 2003).

\section{Self-care behaviour}

The European Heart Failure Self-care Behaviour scale (EHFScB-9) measures self-care behaviours that patients with HF perform to maintain life, healthy functioning and well-being (I). The scale has nine items rated on a five-point scale between 1 (I completely agree) to 5 (I completely disagree). The total score ranges between 9-45, where higher scores indicate worse self-care behaviour. The EHFScB-9 has reported good validity and reliability (Jaarsma et al. 2009).

\section{Heart failure knowledge}

The Dutch Heart Failure Knowledge Scale consists of 15 multiple-choice items measuring HF knowledge in general (4 items), knowledge of HF treatment (6 items), and HF symptoms and symptom recognition (5 items) (I). For each item there are three options, where one option is the correct answer. One point was given for each correct answer, and the total score ranged from 0 (no correct answers) to 15 (15 correct answers). The instrument has been reported to be valid and reliable (van der Wal et al. 2005). The instrument has been 
translated into Swedish using both forward- and backward translation (Wild et al. 2005).

\section{Symptoms of depression}

The Patient Health questionnaire (PHQ-9) measures symptoms of depression (Spitzer et al. 1999) (I, IV). The PHQ-9 instrument consists of nine items. The person should indicate how often they have been bothered by each depressive symptom during the previous two weeks on a scale ranging between not at all (0), several days (1), more than half the days (2) and nearly every day (3). The total score ranges from $0-27$, where higher scores indicate increasing severity. The total score can be divided into different categories, indicating the level of depression severity as mild (5-9), moderate (10-14), moderately severe (15-19,) and severe (20-27). The instrument has been reported to be valid and reliable (Kroenke et al. 2001). The PHQ-9 has been found valid and reliable for measuring symptoms of depression in patients with HF (Hammash et al. 2013).

\section{Health-related quality of life}

The generic instrument EQ-5D three level version (EQ-5D-3L) measures health- related quality of life (IV). The EQ-5D-3L consists of two parts. The first part, EQ-5D descriptive system, comprises five questions referring to the five dimensions mobility, self-care, usual activities, pain/discomfort, and anxiety/depression. Each of these items has three levels; no problems (level 1), some problems (level 2), or extreme problems (level 3). An index score (EQindex) can be calculated with 243 theoretically possible health states, where 1.0 represents full health and the lowest score is -0.59 . The second part, EQ-VAS, reflects the current health status on a vertical thermometer from 0 (worst imaginable health state) to 100 (best imaginable health state) (The EuroQol Group 1990, Brooks 1996). The EQ-5D has been found to be a valid and reliable (Coons et al. 2000). 


\section{Performing caregiving tasks}

Performed caregiving tasks were measured by the Dutch Objective Burden Inventory (DOBI) (IV). The instrument measures objective caregiver burden in partners of patients with HF. The scale can be divided into four domains, task regarding: personal care (11 items), motivational support in following the prescribed treatment regimen (10 items), emotional support (6 items), and practical and treatment related support (11 items), in total 38 items. For each task, the respondent rates how often that specific task was performed during the last three months. Each item is rated on a three-point Likert-type scale ranging from never (1), sometimes (2) to always (3). The total scores for all subscales range between 1 and 3 . Higher scores indicate higher level of caregiving tasks. The instrument has been reported to be valid and reliable (Luttik et al. 2008). The instrument has been translated into Swedish, using both forward- and backward translation (Wild et al. 2005).

\section{Co-morbidities}

The Charlson co-morbidity index (CCI) is a validated method developed to classify co-morbid conditions that may alter the risk of mortality. It is used to summarise the illness burden from co-morbid disease in clinical research. Nineteen different conditions are given assigned weights, 1, 2, 3 and 6 points, where $\mathrm{HF}$ is given 1 point. The $\mathrm{CCI}$ is calculated by summarising each of the conditions in the individual's medical history (Charlson et al. 1987). The score can be classified in three categories; low (0-1 points), moderate (2-3 points), and high ( $\geq 4$ points) (Peterson et al. 2012). The CCI has been reported to be a valid and reliable method to measure co-morbidity in clinical research (de Groot et al. 2003).

\section{Interviews}

To be able to capture the patients' and partners' perspectives of participation in care, individual interviews were performed in the informants' homes (Patton 2002, Kvale \& Brinkmann 2009) (II, IV). The topics and preliminary questions had been developed and tested in a pilot interview with a woman receiving home-care due to HF. Some minor adjustments of the questions were 
made and the same interview guide was thereafter applied during the interviews (II, IV). This pilot interview was not included in the analysis material. To start the interviews, a broad question was asked about what it meant to them to receive home-care due to their HF (II), or what it meant to them as a partner that their loved ones received home-care due to their HF (IV). Thereafter, depending on how the interview proceeded, questions were asked about what participation in care meant to them, how they wanted to participate in care, how they felt about participating in home-care, how they had experienced participation, what they thought about future participation in care, and what prerequisites were needed to participate in care. Probing and follow-up questions were used. The interviews were digitally recorded.

\section{Video-recorded observations}

In order to broaden the understanding of perspectives for patient participation, home visits were observed (Patton 2002) and documented by video-recordings (Botroff 1993) (III). During the preparatory stage, the author video-recorded one home visit to test the data collection method. This videorecorded home visit was studied by the author and two other researches. Video-recording as a method for data collection was considered useful. This test-recording was not further analysed or included in the results.

All video-recordings of home visits were made by the author. The author was present in the setting and managed the video-camera, but did not participate in the care and had no caring responsibility for the patients. The home visit was organised the same way as a regular visit. The patient decided in which room of their home the visit would take place. The recording started after introduction and confirmation of consent, when the patient and nurse were ready to begin the planned home visit. The camera was switched off when the patient and nurse stated that the home visit was ended. Short, descriptive field notes were written in direct connection to the observation to help remembering the context for the visit. In total, six hours and 57 minutes were video documented. Both mean and median time was 22 minutes. The duration for the home visits ranged from 5 to 35 minutes. 


\section{Procedures}

\section{Implementation of The Heart Failure at Home Model}

The four home-care units had all previously provided care for patients with HF, but not followed a specific model. The units had expressed a need to develop care for patients with $\mathrm{HF}$ and a need for education to increase the team members' knowledge and skills in HF care. The team members at the four home-care units were introduced to The Heart Failure at Home Model (Jaarsma et al. 2010a) during an educational day at each unit in January 2010. All components in the model were thoroughly introduced and explained. This also included a discussion about the implementation of the components in clinical practice.

The study nurses at each unit had received additional education about The Heart Failure at Home Model and were also responsible for supporting their colleagues during the implementation of the model. To ensure that the model was implemented throughout the study, the author continuously reinforced and followed the process. Chart reviews and audits, e.g., monitoring of the care plans, access to care and educational strategies were made. The results were continuously discussed with the study nurses and the research team. Structured home-care, based on The Heart Failure at Home Model was first provided when the patients and eligible partners had completed the baseline questionnaire. All patients received all components of the intervention, but the interval of patient contacts (home visits and telephone follow-up) was individualised based on the patient's medical condition, educational, or other needs.

\section{Quantitative data collection (I, IV)}

Patients who met the inclusion criteria were approached by a study nurse and received both verbal and written information about the study. Cohabitant family to the patients' who had accepted to participate (I) were also approached for study participation (IV). Both patients and cohabitant family signed an informed consent. The questionnaires were completed at baseline, 
one, six and twelve months (I), and at baseline and six months (IV). The participants received a pre-paid postage return envelope. One reminder was sent to non-responders after two weeks. Participants who needed help to read the questions and/or fill in the questionnaire were assisted by the study nurses or by the author.

\section{Qualitative data collection (II-IV)}

After the patients and partners had been included for study participation (I, IV), the qualitative data collection started in April 2010. Patients and partners were approached for study participation by a study nurse at the unit and were given verbal and written information. Additional information was thereafter provided by the author. Patients and partners gave written informed consent. The qualitative data was collected in parallel for study II-IV, and interviews with patients were held between April 2010 and February 2011 (II). Videorecorded observations of home visits were made between April 2010 and October 2011 (III), and interviews with the partners were held between April 2010 and June 2011 (IV).

\section{Data analysis}

\section{Statistical analysis}

Descriptive statistics were performed to describe the sample with absolute frequencies (n). To describe scoring of the different instruments, mean (SD) (I) or median (inter quartile range) (IV) were used. No missing values in the scales/indices were imputed. Therefore, those with missing values were not included in the analysis (I, IV). To be able to compare the scoring between the scales/indices measuring different aspects of participation, the values were converted to a percentage of the possible maximum score $(100 \%)$. This calculation was inspired by the instrument developer (I, IV) (Verho \& Arnetz 2003, Arnetz et al. 2008a). To explore if there were age and gender differences between patients who accepted or declined study participation, the chi square test was performed (I). Statistical analysis was performed using IBM SPSS 
Statistics version 20 (I) and version 22 (IV) (SPSS Inc, Chicago, IL, USA). The level of statistical significance was set at $\mathrm{p}<0.05$.

A bivariate correlation analysis using Spearman's rho was performed to explore factors associated with aspects of participation (I). To further explore the relationship, a stepwise linear regression analysis with backward elimination was performed. The choice of predictors for patient involvement, information, patient needs, and overall satisfaction with involvement was based on the results from the bivariate correlation analysis. Factors that had a p-value $<0.10$ were used as predictors for the regression analysis and sociodemographics (age, sex, home-help service and cohabitation), clinical characteristics (NYHA class), knowledge (Dutch Heart Failure Knowledge Scale), symptoms of depression (PHQ-9), and self-care behaviour (EHFScB-9) were included. The variance inflation factor (VIF) was $<2$ in all models of the regression, thereby indicating that there were no problems with multicolinarity in any of the variables.

To describe the patients' view of participation during 12 months with four measurement points, a repeated measure ANOVA was performed for the three scales patient involvement, information, and patient needs, and the single item overall satisfaction with involvement in care. To evaluate if the variance in the differences between all possible pairs of groups (i.e., time) were equal, the Mauchly's test of sphericity was used. The Huynh-Feldt correction was applied if this assumption was violated. To adjust for the multiple tests, the Bonferroni correction was performed (I).

To explore associations between aspects of participation, performing caregiving tasks, health- related quality of life, and depressive symptoms in partners, a bivariate correlation analysis using Spearman's rho was performed. Furthermore, to explore the difference between the partners' score at baseline and six months for the three indices participation, information, and contact, and the three single items, the Wilcoxson signed rank test was performed (IV).

\section{Qualitative analysis}

Data from interviews (II, IV) and video-recorded material from observations (III) was analysed by qualitative content analysis. Content analysis is considered as useful for careful, detailed and systematic examination and 
interpretation of a particular body of data. Content analysis can be used for analysing different kinds of human communication, for instance written documents, audio- or video-recordings of data (Berg 2009). This approach was considered applicable to reach an increased understanding of the phenomenon of participation both from patients' and partners' own descriptions, and from how participation actually occurred during the observed home visits.

The data analysis followed an inductive approach (II-IV), meaning that patterns, themes, or categories from the analysis were derived from data (Patton 2002, Berg 2009). Both manifest content, meaning the surface structure, as well as latent content, meaning interpretation of the underlying meaning, were taken into consideration during the analysis (Downe-Wamboldt 1992, Berg 2009).

All interviews (II, IV) were transcribed verbatim by a secretary. The author validated the transcripts against the audio-recordings. The verbal communication from video-recorded observations was transcribed verbatim by the author. Non-verbal communication was also added to the transcripts from observations (III).

The content analysis process includes several steps, and in this thesis, the steps described by Berg (2009) (II-IV) and Graneheim \& Lundman (2004) (II) formed the basis for the analysis. Initially, the transcripts from the interviews (II, IV) were read repeatedly to gain an overall understanding of the whole. Units of the text that described aspects of participation were marked. The meaning of the units were condensed and labelled with a code (II) or given an open coding close to the participant's statement (IV). These codes were sorted under headings, and preliminary categories (II, IV) and sub-categories (II) were developed. During the analysis, the material was reviewed repeatedly by constantly moving between the whole and the parts. Categories and/or subcategories were grouped and re-grouped and merged during the different steps of the analysis, until the final structure for the findings was established.

The transcripts and the video-recordings were repeatedly read and studied (III) to gain an overall understanding of the whole. The analysis followed the same steps as the analysis of the interviews. However, special efforts were also made to capture the non-verbal communication during the observed care encounters. The author repeatedly examined the video-recordings during the 
analysis to capture and identify non-verbal communication. Non-verbal communication was identified as both integrated among the existing codes, but also as parts that had not been identified and coded earlier in the process. The non-verbal communication that occurred on a more overriding level was described in a separate document and made explicit. This was integrated in the analysis of the whole material.

Categories were created by content that shared similarities and were held together (Patton 2002) (II-IV). When there were threads of an underlying meaning throughout the categories, a theme was created (Graneheim \& Lundman 2004) (III). Descriptions of the categories/sub-categories and themes were made. The N-Vivo 10 (QRS International Pty Ltd, Doncaster, Australia), a software application to organise qualitative data during analysis, was used in study III and IV.

\section{Mixed-method analysis}

A parallel convergent mixed-method design was applied in study IV (Creswell \& Plano-Clark 2011). At first, both data sets were analysed separately through statistical analysis (descriptive and correlation analysis), and qualitative analysis (qualitative content analysis). These analyses gave quantitative results about the scoring of different aspects of participation and performing caregiving tasks. Qualitative findings were revealed in categories describing aspects of participation. Thereafter, the results were examined to identify parts that could be compared. This means that quantitative results and qualitative findings were compared side-by-side, and results that could be compared were examined to see whether the results converged and/or gave an expanded knowledge, or if the results diverged or were inconsistent. The results were presented both as results from the separate analysis and as mixed-method results.

\section{Ethical considerations}

The studies were designed in accordance with and followed the principles of the World Medical Association Declaration of Helsinki (World Medical Association 2013) and the code of ethics for nurses (International Council of 
Nurses 2012). Permission to conduct the studies (I-IV) was granted by the Regional Ethical Review Board in Linköping (DnrM210-09).

Both the information and consent requirements were observed, and patients and partners gave written informed consent (I-IV). It was clarified that participants could terminate their participation at any time, and that this would in no way affect their care or their partner's care. Data collection was done through questionnaires (I, IV), individual interviews (II, IV), and videorecorded observations (III). All qualitative data collection was carried out by the author who was an external person who did not participate in or influenced the patients' care. Participants were guaranteed confidentiality.

A potential risk was that data collection via questionnaires could be perceived as burdensome to the patients or partners (I, IV). The number of instruments was carefully considered, to limit the number of questions as much as possible. Patients and partners were given help to complete the questionnaires if needed.

Asking seriously ill patients to participate in interviews or video-recorded observations of home visits can be regarded as sensitive, especially as patients are in a dependent situation. Furthermore, video-recorded observations of care encounters between patients and nurses in home-care may be particularly sensitive, as they could infringe on the patient's privacy. It was therefore important that both the video-recorded observations and interviews were guided by respect and sensitivity to the patient's situation before, during, and after the data collection. The author has striven to be responsive to any signs of discomfort in the participants, and to be prepared and be able to set aside time to arrange support and management. All participants also had the author's contact details, in case they wanted to contact her about concerns raised by the observed home visits or interviews. None of the participants expressed that they experienced discomfort in association with the interviews or video-recorded home visits. All participating nurses received information about the study and gave verbal informed consent (III). Partners of seriously ill patients are also in a dependent situation, and their interviews were guided by the same sensitivity as the ones with the patients.

Before the interviews or video-recorded observations started, confirmation of previously given consent was repeated. It was again clarified that participants could terminate their participation at any time. All data, including 
questionnaires, transcripts, and video-recorded material, was coded and stored safely and only available to the research team.

\section{Measures to ensure rigour}

Scientific rigour is of importance as it is associated to the worth of the research outcomes (Grove et al. 2013). Depending on whether the research approach is quantitative or qualitative, there are different aspects of the constitution of rigour. Therefore, different steps were taken to ensure scientific rigour in this thesis (I-IV).

\section{Validity and reliability}

In quantitative research, aspects of validity and reliability are considered to be of great importance (Polit \& Beck 2012, Grove et al. 2013). Valid and reliable instruments were chosen for data collection (I, IV). All instruments, except for the two instruments measuring aspects of participation, have previously been used in the HF population or among partners of patients with HF. One of the instruments was developed to measure aspects of participation among patients with myocardial infarction in a hospital setting (I). The other instrument was developed to measure quality of care, including aspects of participation among relatives of patients receiving geriatric care (IV). The choice of items from these two instruments was made in collaboration with the instrument developer. The items were considered applicable to patients with $\mathrm{HF}$ in a home-care context. For the patients, the wording of two items (I) were slightly changed and adapted to the HF home-care context. The instrument was therefore tested by five patients not included in the study. To test the instruments' internal consistency in these studies (I, IV), Cronbach's $\alpha$ or Kuder-Richardson (KR-20) analysis were performed.

\section{Trustworthiness}

In qualitative studies, openness and methodological congruence, thoroughness in data collection, and self-understanding are considered important aspects (Grove et al. 2013). Systematic data collection through semistructured interviews (II, IV), video-recorded observations (III), and systematic 
analysis were applied throughout the studies. This process included openness to the impact of the self during all phases of the process. Four criteria for establishing trustworthiness of qualitative findings were applied; credibility, dependability, confirmability, and transferability (Lincoln \& Guba 1985). To establish credibility, patients and partners were included to ensure variation, using either quota (II) or purposive (III, IV) sampling. During the initial phase of the analysis (II-IV), the author and one or two researchers worked in parallel to establish a foundation for the continued analysis. Thereafter, the author performed the analysis, but had continuous discussions with the researchers throughout the whole process. To ensure dependability, the final structure of the findings were scrutinised by the other researchers. Detailed descriptions of the analysis were also given. To further ensure credibility, quotations (II, IV) or detailed descriptions of the findings, including examples, were given (III). Steps to ensure confirmability were taken through seminar discussions with clinicians and/or researchers about the preliminary findings. Furthermore, the findings were compared to findings from previous studies. To allow for assessment of transferability, descriptive data of participants and context was provided. 


\section{RESULTS}

The overall aim of this thesis was to describe different perspectives of participation in structured heart failure home-care among patients with heart failure and their partners.

\section{Factors associated with patient participation}

This study (I) explored factors associated with the four measured aspects of participation: patient involvement, information, patient needs, and overall satisfaction with involvement in care. The bivariate correlation analysis showed that a lower degree of symptoms of depression, better self-care, higher level of HF knowledge, lower NYHA-classification, male sex, lower age, cohabitation, and having home-help services were associated with one or more of the four scales measuring aspects of participation $(p<0.10)$. The stepwise linear regression analysis showed that self-care behaviour was significantly associated with all four scales measuring aspects of participation $(p<0.001-0.003)$. Symptoms of depression, higher level of HF knowledge, and cohabitation were significantly associated with two of the four scales, while age, sex, and having home-help were associated with one of the four scales measuring aspects of participation (Table 6).

\section{Influence on patient participation by heart failure home-care}

Patient participation was evaluated over time after receiving home-care according to The Heart Failure at Home Model (I). Receiving information about the HF condition and treatment showed a significant change over time. This score received the lowest score at baseline ( $74 \%$ of the max score), and increased to $81 \%$ of the max score at the 12 -month follow-up. Patient needs 
received a fairly positive score at baseline, and received the highest score with $84 \%$ of the max score. The second highest score was given to patient involvement with $81 \%$ of the max score, followed by overall satisfaction with involvement in care with $78 \%$ of the max score. However, none of these three scales showed any significant change over time (Table 7).

Table 6. Factors associated with aspects of participation at baseline.

\begin{tabular}{|c|c|c|}
\hline Outcome variable & Predictor variable & $\mathrm{B}$ (SE) \\
\hline Patient involvement $(n=96)$ & $\begin{array}{l}\text { Self-care } \\
\text { Cohabitation } \\
\text { Age }\end{array}$ & $\begin{array}{l}-0.20(0.05)^{* * *} \\
2.17(0.68)^{* *} \\
-0.08(0.04)^{*}\end{array}$ \\
\hline Information $(n=96)$ & $\begin{array}{l}\text { Self-care } \\
\text { HF knowledge } \\
\text { Female sex } \\
\text { Having home help }\end{array}$ & $\begin{array}{l}-0.24(0.05)^{* * *} \\
0.39(0.16)^{*} \\
-1.52(0.67)^{*} \\
1.61(0.65)^{*}\end{array}$ \\
\hline Patient needs $(n=98)$ & $\begin{array}{l}\text { Symptoms depression } \\
\text { Self-care } \\
\text { HF knowledge }\end{array}$ & $\begin{array}{l}-0.15(0.06)^{*} \\
-0.22(0.05)^{* * *} \\
0.48(0.17)^{* *}\end{array}$ \\
\hline Overall satisfaction involvement $(n=98)$ & $\begin{array}{l}\text { Symptoms depression } \\
\text { Self-care } \\
\text { Cohabitation } \\
\text { NYHA III-IV }\end{array}$ & $\begin{array}{l}-0.09(0.03)^{* *} \\
-0.08(0.03)^{* *} \\
1.06(0.37)^{* *} \\
-1.01(0.58) \mathrm{ns}\end{array}$ \\
\hline
\end{tabular}

Table 7. Changes in patient participation over time based on repeated measure ANOVA.

\begin{tabular}{lllll}
\hline $\begin{array}{l}\text { Time } \\
\text { Mean (SD) }\end{array}$ & $\begin{array}{l}\text { Variable } \\
\text { Patient invol- } \\
\text { vement }(\mathrm{n}=47)\end{array}$ & $\begin{array}{l}\text { Information } \\
(\mathrm{n}=47)\end{array}$ & $\begin{array}{l}\text { Patient needs } \\
(\mathrm{n}=48)\end{array}$ & $\begin{array}{l}\text { Overall satisfaction } \\
\text { involvement }(\mathrm{n}=49)\end{array}$ \\
\hline Baseline (T1) & $19.53(3.44)$ & $14.77(3.43)$ & $23.60(3.72)$ & $7.82(1.80)$ \\
1 month (T2) & $19.28(3.27)$ & $15.96(2.94)$ & $24.54(3.31)$ & $7.96(1.64)$ \\
6 month (T3) & $19.43(3.04)$ & $16.23(3.29)$ & $24.60(3.30)$ & $7.84(1.88)$ \\
12 month (T4) & $20.21(3.26)$ & $16.15(2.98)$ & $24.54(3.31)$ & $7.92(1.64)$ \\
$\mathrm{F}(\mathrm{df})$ & $1.997(3)$ & $4.861(3){ }^{* *}$ & $1.998(2.6)^{b}$ & $0.153(3)$ \\
Post-hoc & & $\mathrm{B} \mathrm{p}=0.009$ & & \\
& & $\mathrm{C} \mathrm{p}=0.008$ & & \\
\hline
\end{tabular}

\footnotetext{
${ }^{* *} p<0.01$

$a=$ Bonferroni corrected $p$-values. Significant differences are reported as, $B=T_{1}-T_{3}, C=T_{1}-T_{4}$

$b=$ Huynh-Feldt correction according to violation of the assumption of sphericity
} 


\section{Patient participation in heart failure home-care}

The patients' own descriptions of participation revealed five main aspects; communication between themselves and health care professionals, having access to care, active involvement in care, having a trustful relation with health care professionals, and options for decision- making (II). The expression for participation during care encounters revealed that participation was made possible by interaction between the patient and the nurse where they mutually influenced each other. An enabling approach, reflected in both patients' and nurses' behaviours during home-care encounters, was identified. The expression for participation was displayed verbally, but could also be enhanced by or expressed through non-verbal communication (III). The importance of different aspects defining involvement was rated as fairly important at baseline. Patients' overall satisfaction with previous participation in care was also given a fairly positive rating. Both scores were stable and showed no significant change over time when receiving structured home-care (I).

\section{Communication in heart failure home-care}

Participation, such as communication between patients and health care professionals/nurses, through information exchange and care-related reasoning had a prominent role in HF home-care (II, III), which was reinforced by an enabling approach during home visits (III). The patients expressed that good condition for communication with health care professionals during home visits, with time and space for a dialogue and exchange of care-related information facilitated participation (II). This communication clearly occurred during the observed home-care encounters, as the patient and nurse interacted in an exchange of care-related information or engaged in care-related reasoning, often while other tasks were performed (III). The dialogue meant that patients could raise concerns and also receive support (II, III). Support and an active interest in the patient became visible as the nurse showed commitment during the home visits. This was expressed both verbally and reinforced by the tone of voice and body language (III). The nurse displayed an enabling approach and invited the patient to a dialogue in various ways during the home visits, for instance through comprehensive questions, explicit questions about the patient's opinion, or joint decisions (III). 
Patients expressed that receiving home-care helped them manage their situation (II). There was an exchange of care-related information during homevisits (II, III), and information could be given about, for instance, the plan for the home-visit, treatment, and self-care actions that could be taken or had been taken (III). Patients' scoring of received information was given the lowest score of the aspects of participation at baseline. However, there was a significant improvement for received information at the six and twelve month follow-ups (I). During home visits, the nurse often initiated exchange of information (III), but patients also gave information (II, III). The interaction increased when this exchange took the expression of reasoning. The topics could be about the plan for the visit or treatment, and was developed through interplay between the parties. This reasoning could also take place while other tasks were performed and was reinforced by body language (III). During home visits, patients asked questions (II, III) and showed an active interest (III). Patients described the importance of receiving continuous information and how knowledge helped them to handle their situation (II). The patients also displayed their knowledge, for instance, about symptoms, monitoring, and treatment during home visits (III). Patients described a transparency in home-care, as documentation and other activities were visible to them, and they expressed an understanding of the steps taken during the visits (II).

\section{Accessibility and fulfilled needs}

Participation was also expressed as having access to care, including an awareness of the plan for home visits, and involvement in this planning. Having an opportunity to initiate visits if deterioration occurred was expressed as important for participation, and was different to other care contacts (II). Patients scored fulfilled needs in terms of asking questions, understanding information and being treated with respect rather positively at baseline. This remained stable over time and showed no significant changes (I).

\section{Active involvement in care}

Patient participation included active involvement in care (II, III). Patients performed different kinds of self-care and described how they used their experiences and knowledge to manage the situation (II). Participation was 
expressed as collaborative care with health care professionals, as patients, for instance, prepared themselves prior to home visits. They also discussed appropriate medication or levels for monitoring with health care professionals (II). During the care encounters, an enabling approach included active interest by the patient and the nurse who invited to a dialogue, and this displayed how collaborative care occurred (III). Collaboration also took place in terms of performance of practical care (II, III). This became visible during home visits as patients and nurses interacted when practical tasks were performed, e.g., prior to, during, and after check-ups. Interaction expressed through collaboration displayed different levels of intensity and included both verbal and non-verbal communication. Collaboration could take place without prior verbal communication, which displayed that the patient was familiar with the procedures during home visits (III). An enabling approach underpinned this collaboration (III).

\section{Trustful relations}

Patients described that a trustful relation with the health care professionals was an important foundation for participation. This included confidence in the health care professionals' competence and individually adapted care (II). During the observed home visits, a trustful relationship could be traced when patients and nurses displayed an enabling approach, which in turn enabled participation (III). Having confidence in the health care professionals and being able to rely on them providing sufficient care was important for participation (II). The nurses also showed that they trusted the patients' information, e.g., when recording data of the patients' own observations prior to the home visit (III). Patients expressed that they could lack sufficient knowledge to manage their situation, but that they used previous experience and knowledge to assess the care provided. Having the same health care professional coming for home visits facilitated participation, as the health care professional was then aware of the patient's own knowledge and preferences. A trustful relation also included care based on the patient's needs and a genuine concern for the patient (II). Concern was displayed during home visits when the nurse showed commitment to the patient. This was expressed when the nurse actively listened to the patient and took their starting point in the patient's situation, and also invited the patient to a dialogue. These verbal expressions for commitment were also reinforced by non-verbal communication. A slow pace, and being present, for instance by pausing the 
task performed when the patient explained something, allowed for participation (III).

\section{Expressions of own preferences for participation}

The patients described different aspects of decision-making. The majority expressed preferences for participation and a will to be involved in discussions and/or influence decisions (II). During home-visits, patients' participation was enabled when they explicitly expressed their will. For instance, patients gave instructions prior to performing check-ups or measurements, or expressed their will about postponing the next visit (III). Patients described that their preferences for participation were connected to their knowledge and personality, and it was their own responsibility to comment if they did not agree. Patients gave examples of how the health care organisation could restrict the possibility for making decisions (II). Patients also described their will to entrust decisions to the health care professionals. This could be done by a passive approach or an active approach and handing over the decisions, but they wanted to have information and be involved in discussions (II).

\section{Barriers for participation}

Most of the findings showed positive experiences, but the patients' descriptions of participation also revealed various obstacles. Restricted time and space for a dialogue, and lack of information about the organisation of care had a negative impact on participation. Furthermore, lack of trust or confidence in the health care professionals, different health care professionals coming for home visits, or an underestimation of the patient's knowledge were barriers for participation. Lack of possibility to influence the care content, or if no options were given could also have a negative influence on participation (II).

\section{Partners' experiences of participation}

Partners scored fairly positive for the measured aspects participation, information, contact, and overall satisfaction with participation. All scored between $80-94 \%$ of the max score at six months (IV). There were no significant differences for the measured aspects of participation between baseline and six 
months. The bivariate correlation analysis showed a significant association between both received information and overall satisfaction with participation in care and better health, measured by EQ-VAS (rho ranging between 0.56$0.71, \mathrm{p}<0.05)$. Practical and treatment related tasks received the highest score, followed by emotional and motivational support. Personal care received the lowest score. The bivariate correlation analysis also showed a significant association between a higher degree of participation in care to the extent that they wanted and three of the DOBI-subscales (rho ranging between 0.56-0.70, $\mathrm{p}<0.05)$, except for the subscale for practical care.

The partners' descriptions of participation in care resulted in four categories. Two were more linked to participation in relation to the patient, and two were more related to participation with health care professionals. The quantitative results of aspects of participation and performing caregiving tasks could be mirrored in the content of the qualitative findings. A summary of the side-byside comparisons is displayed in Table 8.

The first category revealed that participation took place in relation to adapting to the caring needs and illness trajectory. This meant that partners were involved according to the patient's health situation and needs, e.g., practical involvement in the patient's care, and various aspects of self-care and support. The need for partner involvement ranged widely. This finding was convergent with the scoring of performing practical and treatment related tasks. The qualitative findings also expanded the understanding of involvement with regard to performing personal care. The sub-scale personal care was scored rather low. This meant that partners scored that they did not perform that much care. However, the partners' descriptions revealed that some of the patients had substantial care needs.

The second category revealed that participation included mastering caregiving demands. Partners' will to be involved ranged from no will to be involved, to being utterly involved. Partners expressed that it was their duty to support and care for the patient, this reflected both positive and negative emotions. Lack of knowledge lead to a feeling that they could not be responsible for the patient's care. These qualitative findings expanded the understanding of the scoring regarding what it meant to be satisfied with participation and involved to the extent that they preferred. This could mean that the partners' actual involvement in care could range widely. Furthermore, partners did not 
experience any particular demands from care providers at present, but some expressed a fear that such demands would follow.

Table 8. Summary of side-by-side comparisons of partners' descriptions of participation in care, and scoring of aspects of participation and performing caregiving tasks (IV).

\begin{tabular}{ll}
\hline Qualitative categories & Quantitative results (n=14) \\
& Median (Q1; Q3) \\
\hline
\end{tabular}

Adapting to the caring needs and illness trajectory The partners were involved in relation to the patient's' health situation and needs. The needs varied from being limited to extensive.

Mastering caregiving demands

The partners' willingness to be involved in care ranged from no will to be involved to be utterly involved. Partners expressed their responsibility to support the patient, this reflected both positive and negative emotions.

Interacting with health care providers

The partners were present during visits, but their activity varied. They provided information to the health care professionals who paid attention to them. The partners had good opportunities to make contact and ask questions.

Gaining knowledge to comprehend the health situation The partners expressed a need for information, and they also received information about different aspects of care and treatment.

\section{Caregiving tasks:}

Practical and treatment related tasks $2.5(2.0 ; 2.9)$

Motivational care $1.7(1.1 ; 2.0)$

Personal care $1.2(1.1 ; 1.6)$

Overall satisfaction participation in care $8.0(7.0 ; 9.5)$

Participated to the extent they wanted, $4.0(3.0 ; 4.0)$

Perceived too high demands, $2.0(1.0 ; 3.0)$

Participation in care* $11.0(7.5 ; 12.0), 92 \%$ of max score

Contacts $10.0(8.0 ; 12.0), 83 \%$ of max score

Information $15.0(12.8 ; 16.0), 94 \%$ of the max score

${ }^{*} n=13$

Performing caregiving tasks: score range 1-3, a higher score indicates performance of more tasks, Overall satisfaction participation in care score range 1-10 higher score indicates more positive rating, Participated to the extent they wanted and Perceived too high demands $4=$ Yes, to a great degree, $3=$ Yes, somewhat, 2= No, not especially, $1=$ No, not at all.

The third category described participation by interacting with health care professionals. Partners were often present during home visits, but their activity level during these visits varied. They provided information, had an opportunity to ask questions, and felt that the health care professionals paid attention to them. The partner could also be the person initiating and managing the patient's care contacts. These findings converge and complement our understanding of the scoring for both participation in care and possibility to make contact. Both received a fairly high and positive score.

The fourth category, gaining knowledge to comprehend the health situation, described the partners' continuous need for information about different aspects of care, and that they also received information. Being informed 
included having knowledge of a range of aspects related to the disease. These findings converge as received information was given a high and positive score. These results also expand the understanding of the meaning of this information.

\section{Comprehensive description of participation in heart failure home-care}

Overall, patients and partners expressed positive experiences regarding participation in HF home-care (I, II, IV). This included the importance of having access to care, which also meant safety (II, IV). Participation became visible during observations of home-care encounters between the patient and nurse (III). Participation in terms of communication between patient and health care professionals had a prominent role in the patients' descriptions (II). Furthermore, a trustful relationship with health care professionals, options for decision-making and active involvement in care, was important aspects for participation (II). These aspects were visible and identified during the care encounters (III) and were confirmed in the measurements of different aspects of participation in care (I). The results that describe the patients' different perspectives of participation (I-III) showed that some had a strong and consistent reciprocal relationship, some showed an explicit reciprocal relationship, and some had relationship, but on an underlying level. The results and how these different perspectives are related to each other are displayed in figure 3. Communication and interaction with health care professionals were also important aspects in the partners' descriptions. These were confirmed in the measured aspects of participation in care (IV). Overall, the results from the different studies showed results that converge and can be related to each other. 


\section{PATIENTS' DESCRIPTIONS OF PARTICIPATION (II)}

\section{Communication between} patients and HCPs

- Time and space for dialogue

- Exchange of care-related information

\section{Accessibility to care}

- Awareness of the

plan for home visits

- Feasible to initiate visits

Active involvement in care

- Performing self-care

- Collaborative care with HCPs

Trustful relation with HCPs

- Confidence in $\mathrm{HCP}^{\prime}$ 's competence

- Individually adapted care

Options for decision-making

- Making decisions

- Entrusting decisions

\section{PARTICIPATION IN CARE ENCOUNTERS (III)}

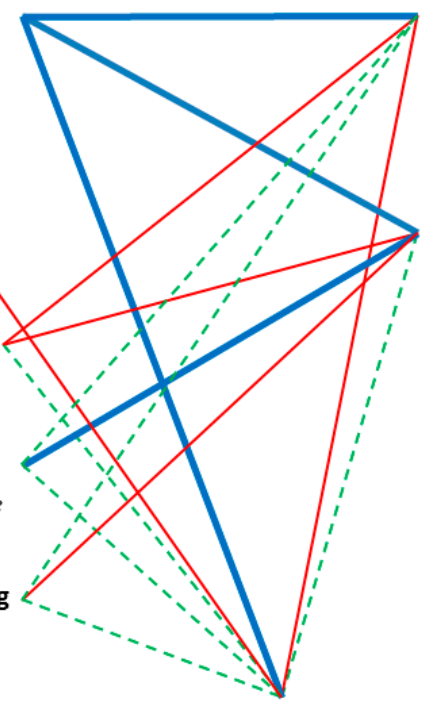

Participation in the care encounter is made possible by interaction

- Exchange of care-related information

- Care-related reasoning

- Collaboration

Participation in the care encounter is made possible by an enabling approach

- The patient expresses own wishes

- The patient shows an active interest

- The nurse is committed

- The nurse invites to a dialogue

\section{PATIENTS' SELF-REPORTED PARTICIPATION (I)}

- Patient involvement

- Information

- Needs

- Overall satisfaction

Figure 3 Overview of perspectives for patient participation in HF home-care (I-III), and how these perspectives are related to each other. The different perspectives were derived from ; patients' descriptions of participation (II) five categories including two sub-categories each, participation during observed home-care encounters (III) two themes including three and four categories each, patients' self-reported participation (I) four aspects.

The relationship is displayed on three different levels;

_ shows a strong and consistent reciprocal relationship between the findings

- shows that there is an explicitly expressed reciprocal relationship between the findings

- - shows that there is an underlying relationship between the findings

HCPS $=$ health care professionals 


\section{DISCUSSION}

\section{Discussion of the results}

This thesis describes different perspectives of participation among patients and their partners in structured HF home-care. To our knowledge, there are no previous studies with this specific focus on participation in this HF care context. Many of the patients who received home-care were frail, had severe $\mathrm{HF}$, and were highly symptomatic. In the studies, both patients and their partners stated that home-care facilitated participation in care. Overall, both patients and partners were satisfied with most aspects of participation in relation to home-care. Interaction and an enabling approach between involved parties, including satisfactory communication and sufficient information, facilitated patient participation. Patients wanted to be, and were involved in their care, but extent and manner varied. A trustful relationship was described as a foundation for participation. There were also barriers for patient participation, primarily due to insufficient organisation of care or a lack of confidence in health care professionals. Having access to home-care was of great importance for participation, both for the patients and their partners. The partners' participation was related to the patient, as they had to adapt to caring needs and master caring demands. Partners' participation was also related to health care professionals. They described that participation was facilitated by interaction with health care professionals and the opportunity to gain knowledge about HF care.

\section{Factors associated with patient participation}

Based on the literature, factors found to be associated with aspects of participation in the group of patients with HF were identified. Out of these, seven factors (sex, home-help service, cohabitation, NYHA class, knowledge symptoms of depression and self-care behaviour) were found to be associated with one or more of the four aspects of participation (involvement, 
information, needs, and overall satisfaction with involvement) (I). Two factors, self-care and HF knowledge, were of specific interest in relation to care for patients with HF.

Self-care behaviour was consistently associated with all four aspects of patient participation (I), and this association has to our knowledge not been identified before. Better self-care behaviour was significantly associated with more positive ratings in the four aspects of participation. As increased self-care improves outcomes such as mortality and morbidity (Lee et al. 2011), aspects of patient participation need to be highlighted and prioritised when planning and delivering HF care. When patients perform self-care they are active and participate in their own care (Riegel et al. 2012). Similarities between self-care and participation as found in this thesis, have been confirmed in a systematic review of qualitative studies summarising patients' perspectives of self-care needs (Currie et al. 2014). A good relationship between patients and health care professionals was found to be a facilitator for HF self-care. This relationship included interaction, and self-care was supported when health care professionals were accessible, respectful, attentive, and collaborative (Currie et al. 2014). Patient participation in HF home-care was founded on a trustful relationship between patients and health care professionals that includes interaction through communication and collaboration. Interaction between patients and nurses was also identified during the observed home visits. This underlines the potential for support and improved self-care when there is a high level of patient participation in a home-care setting. However, our results cannot determine if self-care affects participation or if it is the opposite case. The association is probably reciprocal.

Better HF knowledge was significantly associated with the aspects of participation, higher ratings for received information and fulfilled needs (I).This result is in concordance with previous qualitative findings that have described the importance of knowledge in relation to participation (Larsson et al. 2007, Eldh et al. 2010), and with the patients' descriptions (II). This association between knowledge and aspects of participation could also be of interest for HF self-care. Knowledge is important to be able to perform sufficient HF self-care (Strömberg 2005, Riegel et al. 2012). However, the relationship between self-care and knowledge is complex, and studies show that increased knowledge does not always mean better outcomes with regard to HF self-care (Boyde et al. 2011). 


\section{Patient participation in heart failure home-care}

Perspectives of patient participation in this thesis reveal a broad picture (I-III), which is in line with previous descriptions of the concept as being multifaceted (Cahill 1996, Sahlsten et al. 2008). The group of patients receiving home-care had advanced HF and most of them had experienced multiple care contacts during their illness trajectory. The results in this thesis describe participation with regard to the home-care context, but should also be understood as being influenced by the participants' previous experiences.

Patients with HF receiving structured-home care wanted to be involved in their care, but what this involvement included, differed between patients (II). Patients reported it to be of rather high importance for participation to receive clear information, have ability to ask questions, express own views, participate in discussions, make decisions about care and treatment, and bear the main responsibility for their health (I). This rating of the importance of the aspects defining participation is comparable to patients hospitalised due to an acute myocardial infarction (Arnetz et al. 2008a). The patients also reported that they were rather satisfied with their overall participation in HF home-care (I).

Patients' preferences for participation regarding decision-making about care and treatment vary in previous research literature (Schoot et al. 2005, Say et al. 2006, Rodriguez et al. 2008, Burton et al. 2010, Ekdahl et al. 2010, 2011, Foss 2011). This is confirmed in this thesis, where patients' willingness to make decisions also varied (II). Some patients explicitly expressed their views and preferences regarding some actions taken during the visit, and they also took an active role in decision-making (II, III). Others did not want to make decisions and entrusted themselves to the health care professionals' care (II). However, most of the findings revealed that care was planned in consultation with patients (II, III). This is of importance in order to meet legal requirements for participation in care (Socialdepartementet 1982, 2014), and respect the patient as a person (McCormack \& McCane 2006).

Patients' descriptions revealed that there was often room for a dialogue during home visits, which was also important in order to gain knowledge (II). This dialogue could be identified during the observed home-care encounters (III), underpinned by interaction and an enabling approach by both parties. The exchange of care-related information included both parties, as patients shared their experiences and information and nurses shared their professional 
knowledge and experiences with the patient. This patient-centred communication has shown to be important for patient satisfaction, but also to improve adherence and patient health (Charlton et al. 2008). Patients could also receive confirmation of their own concerns during the home visits, which was important for managing the situation (II). According to these findings, conditions for communication during home visits seem to be rather favourable compared to other HF care contexts (Barnes et al. 2006b, Howie-Esquivel \& Dracup 2012). The fact that patients rated a significant improvement over time for received information supports this (I). Receiving sufficient information about care is one important aspect for meeting legal requirements for care (Socialdepartementet 1982, 2014), and also for patient satisfaction with care. Home visits often meant good conditions for exchange of care-related information (II, III), which patients emphasised as being highly significant for participation (II).

Patients described active involvement in care, and if and how this influenced self-care. Patients performed self-care and collaborated with health care professionals (II), and the mutual activity seemed to help them gain control. Patients' active involvement could also be identified during the observed care encounters, where discussions with the nurses about different aspects of selfcare were highly present (III). Having self-care skills is desirable; both tactical skills (how to) and situational skills (what to when) (Dickson \& Riegel 2009). However, findings from a qualitative meta-analysis revealed that traditional patient education does not always support the development of these skills (Dickson \& Riegel 2009). Participation with regard to patients' active involvement and performed self-care (II) could have the potential to support both tactical and situational skills when faced with new situations, e.g., deterioration with symptoms of breathlessness. Patients used their knowledge and previous experience in new situations to respond and handle their selfcare. If this was supported by care and education taking place in the home environment is difficult to determine. However, home-care may provide an opportunity to obtain a more complete picture of the HF patient's situation, including the ability to manage their condition at home (Jaarsma \& Luttik 2011). This may lead to more tailored patient education, thus facilitating knowledge exchange. Individualised self-care education was one important part of structured HF home-care, and patients also described that the knowledge they obtained helped them to handle their situation (II). The patients were fairly knowledgeable about HF when they were enrolled in structured home-care (I), but there is a constant need for more knowledge in 
order to handle upcoming situations related to the HF condition (Riegel et al. 2012, Wingham et al. 2014).

Having a trustful relationship with health care professionals was of great importance and facilitated participation (II). Many of the observed home-care encounters bore witness of confidence between the parties involved. Patients were active and expressed their own wishes, and nurses showed commitment and invited patients to a dialogue (III). Previous research has described that participation in care can be stimulated if the patient is recognised and experiences a genuine interest from the health care professionals (Larsson et al. 2007), and that encounters between equal partners who interact during care facilitate participation (Schoot et al. 2005, Tutton 2005, Millard et al. 2006). This was in concordance with findings in this study (III). The fact that care was provided in the patient's home probably influenced participation, as revealed in this thesis. The importance of trustful relationships with health care professionals has been described by patients receiving home-care (Brännström et al. 2006, Skär \& Söderberg 2011, Holmberg et al. 2012). Health care professionals have also described seeing themselves as a guest in the patient's home (Öhman \& Söderberg 2004, Brännström et al. 2005). This might lead to a more equal relationship between the patient and health care professional, which probably facilitate participation. This finding could be compared to descriptions of participation in care within hospital settings, where room for patient participation sometimes was more limited (Wellard et al. 2003, Eldh 2004, 2006b, Frank et al. 2009, Larsson et al. 2011a, b, Ekdahl et al. 2012). However, other findings have revealed that patients sometimes experience a lack of trust in health care professionals, and that this has a negative influence on the outcome of the visit, and also on participation (II). Lack of interaction and relationship, caused by lack of continuity and collaboration, has previously been explained as non-participation among patients with HF (Eldh et al. 2004). Patients described that when there was a lack of confidence they became more withdrawn and refrained from asking questions (II). This had a negative impact, as the patient had questions that remained unanswered until the next visit. Furthermore, it could also entail a risk that information about early signs of deterioration were not recognised during the home visit, and in the worst case scenario, lead to a more severe progression of symptoms.

Patients' experiences prior to being admitted to home-care revealed that they sometimes had to struggle to receive help when symptoms deteriorated. Being able to influence their situation and have easy access to care and support when 
needed was of great importance for participation (II). Both being aware of the plan for home visits and being able to initiate visits were described as highly important for participation and feeling safe. This experience of safety is in concordance with previous findings in patients with HF receiving palliative home-care (Brännström et al. 2006). Access to care also meant increased patient involvement among older patients in other care contexts (Bastiaens et al. 2007). One of the components in The Heart Failure at Home Model (Jaarsma et al. 2010a) is to increase access to care, which was in line with the finding from this study (II).

\section{Partners' experiences of participation}

Partners of patients with HF receiving home-care described participation in care, both with the patient and health care professionals (IV). Previous research has also reported that family and partners are involved in different aspects of care (Clark et al. 2008, Rosland et al. 2010, Piamjariyakul et al. 2012). For the patient, the fact that the partner is involved in their care is of great importance (Piamjariyakul et al. 2012). From the partners' perspective, this need for their involvement could be experienced as both burdensome (Saunders 2008, Ågren et al. 2010), but also associated with positive experiences (Hogstel et al. 2005, Kang et al. 2011, Gusdal et al. 2014). This continuum ranging between positive and negative experiences was also revealed by partners' descriptions of participation (IV). Partners needed to adapt to caring needs and caregiving demands, which reflected both negative and positive experiences of participation. The extent to which partners actually participated in the patients' care varied greatly.

Overall, partners scored that they were fairly satisfied with the different aspects of participation in home-care, which was strengthened by their descriptions of participation in connection with home visits. Partners' participation in relation to health care professionals during home visits revealed interaction and good conditions for communication. They described the importance of receiving care-related information as this gave them the knowledge to comprehend the patients' health situation. These findings also showed several similarities with the patients' descriptions of participation (II). Both patients with HF and their partners have described a continuous need for knowledge acquisition (Liljeros et al. 2014), which is in concordance with findings from this study (IV). Previous research has also described how 
partners of patients with HF experience involvement when they are included in care, given attention, and are recognised (Mårtensson et al. 2001). This could be compared to the partners' descriptions (IV). Partners had negative experiences if they were kept at a distance, did not receive sufficient support from health care professionals (Mårtensson et al. 2001), and had to struggle to be included in contacts with health care professionals (Gusdal et al. 2014). Partners also lacked information about prognosis and what would happen in the future (Imes et al. 2011). These negative experiences were not found in this study (IV). It is difficult to determine if this was due to a non-existence of negative experiences, or if these just were not expressed. Care provided in accordance with The Heart Failure at Home Model (Jaarsma et al. 2010a) aimed to plan care in collaboration both with the patient and their family, and also to involve the family in education. The findings point out several positive experiences of this. Furthermore, partners also expressed the importance of easy access to care when the patient received home-care and how this meant safety.

\section{Methodological considerations}

Overall, the combination of methodologies aimed to gain a better understanding of different perspectives of participation among patients with HF and their partners in a home-care context. By method triangulation, weaknesses of a single methodological approach could be diminished (Patton 2002, Polit \& Beck 2012). Collecting data from different sources (I-III, IV), where comparisons of the results in many ways showed converging results, could be considered a strength for the results in this thesis. However, there are some methodological limitations.

\section{Sample}

A consecutive sample of 100 patients was determined feasible for inclusion in study I. No prior power calculation was performed for sample size, which could be regarded as a limitation (Altman 1999). The sample ran a risk for selection bias for two reasons: the large number of patients who declined to participate, and the large number of patients assessed as unable to participate in the study. No age or gender differences were found between those who 
participated and those who declined. No further analysis of other clinical or demographical differences between the groups was performed, and this must be considered as a threat to internal validity. The mortality rate was high among the patients during the one- year follow- up. Forty-two of 100 patients had deceased after one year, and this is also a limitation for the internal validity.

There are no specific rules for sample sizes in qualitative studies (Patton 2002). The inclusion of participants aimed to reflect the group of patients receiving home-care (II), or reflect a variation in age, gender and different care needs (III). The inclusion of participants aimed to capture different perspectives and data that were as rich as possible. The mean age of those who accepted to participate was slightly younger compared to the whole group of patients receiving HF home-care. However, the participants' age ranged quite widely. Nine of the patients who participated in the video-recorded observations (III) were also interviewed (II), but these interviews were conducted at a later date. This may indicate that some of the included patients (II, III) reflected a group of patients who were more positive or had a specific interest for participation. This might have influenced the findings. The sample of partners (IV) was done to reflect a variation in age, gender, and being a partner of a patient with different care needs. The included partners were considered to reflect this in the group of eligible partners. However, the final sample of included partners was low, which could be regarded as limitation for the mixed- method design.

\section{Implementation of structured home-care}

The implementation of The Heart Failure at Home Model (Jaarsma et al. 2010a) was followed thoroughly throughout the study. The repeated audits and chart reviews at the home-care units to ensure that the model was followed were a strength (Polit \& Beck 2012). The care for each patient was determined by the patient's health status and needs. The number of home visits varied between patients. Furthermore, due to organisational differences at the four home-care units, some patients remained enrolled, whereas other patients were discharged during the year of follow-up. However, we only comment on changes in participation with regard to receiving structured home-care. 


\section{Data collection}

The measurement properties for most of the instruments had previously been tested for satisfying validity and reliability, and been applied in studies with patients with HF or their partners. The majority of the instruments also showed satisfying results for internal consistency (I, IV). However, the Swedish version of the Dutch Heart Failure Knowledge Scale (van der Wal et al. 2005) (I), and the DOBI-instrument (Luttik et al. 2008) had not previously been tested for validity and reliability in a Swedish sample. The translation of the instruments followed established steps for translation and was done in collaboration with the constructors of the scales (Wild et al. 2005). The test of internal consistency for the DOBI scale was satisfying (IV), but internal consistency for the knowledge scale showed low results (I). We probably should not expect to find internal homogeneity of the items in this type of knowledge scale (Streiner \& Norman 2003). The low value probably reflects the problem of testing internal consistency in this type of scale, rather than problems with reliability due to the translation of the scale. The wording was slightly changed in a few items in the scales/indices measuring aspects of participation for patients (Arnetz et al. 2008a), and for partners (Verho \& Arnetz 2003). These changes were made to adapt the instruments to patients with HF and partners in a home-care context. Tests for internal consistency showed satisfying results for these instruments (I, IV). Five patients completed the questions in the instrument for patients, without reporting any problems (I). Further tests for validity and reliability of the instruments had been preferable, as the instrument was used in a new population and changes had been made (Polit \& Beck 2012).

An interview guide was developed to ensure that the same topics were explored during the interviews (II, IV). It also provided room to build the conversation about the phenomenon of interest (Patton 2002). All interviews were conducted by the author in the informant's homes. This was a wellknown environment for the informant. Before the interviews started, contact was established through small talk and talk about the informant's background. This was of importance to make informants feel safe and relaxed during the interview (Kvale \& Brinkman 2009). However, the quality of the interviews varied with regard to both length and depth (II, IV). The phenomenon of participation could be viewed as rather abstract, which was also reflected during the interviews. Some informants' narratives were short and succinct, while others were more rich and detailed. Some interviews with patients had 
to be terminated early due to their health situation (II), but these interviews gave important insights from people with rather symptomatic HF. However, the quality of the interviews may have affected the credibility for the study (Lincoln \& Guba 1985).

Video-recorded observations allowed collection of rich data and reduced the risk for data loss, compared to field notes (Botroff 1993) (III). On the other hand, this also lead to a risk that the presence of an observer affected the course of events (Patton 2002). The participants had initially been given written information that the study focused on participation in care encounters. This was thereafter not discussed, neither with the patients nor the nurses, either prior to or in connection with the observations. The verbal information focused on the fact that the author would attend during the visit and that the visit followed normal procedure. Furthermore, information was given that the visit would be observed and video-recorded by the author. The initial information could have affected the events during the video-recorded observations and could be considered as a limitation for the study. The presence of the author managing the camera was noticed by patients and nurses, and may also have affected the events during the visit. During most of the video-recorded observations, the patient and/or the nurse made short comments about the camera presence. However, they then became occupied with conversations and tasks to be carried out. During the preparation phase the author had followed different nurses to several home visits. No major differences could be identified between non-recorded or video-recorded home visits. One possibility was that the author's presence also affected these nonrecorded visits. However, both the results from the measurements of participation and interviews correspond in many ways with findings from the observations. This strengthens the credibility of the findings that emerged during the observations.

\section{Data analysis}

Quantitative data was analysed with established statistical methods (I, IV). However, the scales were treated as continuous variables in both the regression and ANOVA analysis (I). This choice was made due to a lack of a non-parametric alternative for the multiple regression analysis. Therefore, these analyses were performed, but could be considered as a limitation (Altman 1999). Due to some predictor variables only being ranked as categorical (I), Spearman's correlation was used. There are divergent views in 
the literature on how different kinds of scales should be handled (Knapp 1990). A post-hoc power calculation was performed, showing a power problem to detect a small effect, but the power was sufficient to detect a medium effect for the findings in the repeated measure ANOVA.

The same methodological approach, qualitative content analysis, was applied in three studies (II-IV). The analysis was performed systematically following described steps, and could be considered as a strength for credibility (Lincoln \& Guba 1985). The analysis was carried out with a desire to be open to data and be aware of own pre-understandings during the analysis. Assessing this is difficult, but the author and one or two researchers initially analysed five (III, IV) or six (II) interviews and observations separately. This was followed by discussions to establish a mutual understanding and foundation for the rest of analysis. Thereafter, the author conducted the analysis. Having two people perform all analyses could have been one way to further strengthen credibility and confirmability. However, there were close cooperation and discussions with the other researchers throughout the analysis. Finally, a critical review of the findings was performed by one researcher. This person had not been that closely involved during the analysis. This strengthens credibility, dependability, and confirmability of the findings (II-IV).

The mixed- method analysis gave an expanded understanding of the possible meaning of partners' participation in the patients' care (IV). However, handling two data sets concurrently during the mixed- method analysis was a complex task. Developing a joint display for comparisons of the qualitative and quantitative data was one way to strengthen validity in the mixedmethod analysis (Creswell \& Plano Clark 2011). There were close cooperation and discussions between the researchers also in the mixed-method analysis.

\section{Generalisability and transferability}

The study that described the influence of structured home-care in participation and explored factors related to participation (I) was based on a small consecutive sample. The mean age for included patients was higher than in the Swedish HF population (Zarrinkoub et al. 2013). The fact that patients had rather symptomatic HF could limit the external validity. This affects the generalisability of the results to the whole group of patients with HF. However, the results could be generalised to patients with HF receiving homecare. The findings from the qualitative studies that described patients' 
perspectives of participation (II), and participation in care encounters (III) could be transferable to patients with HF receiving home-care in a similar context. The results that describe partners' perspectives of participation (IV) could be transferable to partners of patients with HF who receive home-care in a similar context.

\section{Conclusions}

- Heart failure home-care facilitated participation in care, both for patients and their partners.

- Access to home-care meant safety both for patients and their partners.

- Higher ratings of the different aspects of patient participation were consistently associated with better HF self-care behaviour.

- After receiving structured home care there was a significant improvement in patient participation with regard to received information over time.

- Satisfactory conditions for communication, having influence on access to care, active involvement in self-care and care, trustful relationships with health care professionals and options for decision-making were aspects of patient participation in heart failure home-care.

- Interaction and an enabling approach in HF home-care underpinned patient participation, as both patients and nurses contributed to making participation possible.

- Partners' participation in care meant adapting to the patients' caring needs and mastering caregiving demands.

- Partners interacted with health care professionals during home visits and had the possibility to gain knowledge, which facilitated comprehension of the health situation.

- Partners were mainly satisfied with their participation in care when the patient received HF home-care.

\section{Clinical implications}

The results from this thesis can be used for further development of HF homecare, in order to enable participation for both patients and their partners. Patients with HF and most partners wanted to be involved in care, but the extent and manner of involvement varied. Therefore, patients' and partners' 
preferences for participation in care need to be individually assessed and not assumed. Home-care where patients have easy access to care is of great importance for both patients with HF and their partners, in order to experience participation and safety. Sufficient time and space that enable a dialogue between parties during home visits is highly important for participation. This facilitates exchange of care-related information and knowledge, and increases patients' self-care. Organising care with continuity between patients and health care professionals is also important for building trustful relationships that enable participation and active involvement in care. This is also of importance to support the patients' development of self-care skills. Many partners are involved in patient care and have an ongoing need for information. To facilitate participation there is a need for care that provides an opportunity to ask questions and reciprocal information exchange. This enables partners to comprehend the health situation and thereby support patients.

\section{Future research}

In this thesis, associations between different aspects of participation and selfcare, and between participation and knowledge were found. However, to gain a deeper understanding and be able to explain causal relationships, as well as explore factors that mediate or moderate this relationship, further studies are needed. Furthermore, exploring whether this relationship between participation and self-care is constant or changes over time could also be of interest. For this, larger longitudinal studies are needed.

The results from this thesis could be used to develop an intervention that specifically targets improved participation for patients with HF and their partners, and for improving self-care, HF knowledge and satisfaction with care.

The qualitative findings in this thesis could also be used to further develop the instruments measuring aspects of participation in both patients and partners. These instruments can be useful both for evaluating interventions and clinical practice with regard to patient and partner participation. 



\section{SVENSK SAMMANFATTNING}

Delaktighet i vården har varit i fokus under de senaste årtiondena. I de lagar, föreskrifter och direktiv som reglerar hälso- och sjukvården poängteras vikten av patientens delaktighet. Hjärtsvikt är ett kronsikt sjukdomstillstånd som påverkar ett stort antal personer runt om i hela värden. När sjukdomen framskrider leder det till tilltagande symtom och att genomföra adekvat egenvård är därför av stor vikt. Patienter med hjärtsvikt har ofta ett utökat vårdbehov och hemsjukvård kan då vara en möjlig vårdform. Tidigare forskning om hur patienter med hjärtsvikt och deras partner beskriver sina erfarenheter av delaktighet $\mathrm{i}$ vården är begränsad. Forskning om delaktighet $\mathrm{i}$ förhållande till patienter med hjärtsikt som får hemsjukvård är än mer begränsad.

Avhandlingens övergripande syfte var att beskriva olika perspektiv av delaktighet, hos patienter med hjärtsvikt och deras partners, i samband med strukturerad hemsjukvård.

Alla patienter som ingick i avhandlingen erhöll strukturerad hemsjukvård utifrån en modell som har målsättningen att underlätta för patienten i vården, där trygghet, delaktighet och att ha kunskap om sin sjukdom och behandling, är i fokus. I den första delstudien ingick 100 patienter med hjärtsvikt som fick strukturerad hemsjukvård. Patienterna besvarade frågeformulär där resultatet visade att det genomgående fanns ett samband mellan mer positivt skattade aspekter av delaktighet och bättre egenvård. De patienter som följdes upp under 12 månader, skattade en signifikant förbättring gällande erhållen information, som var en av de aspekter av delaktighet som mättes.

I den andra delstudien intervjuades 19 av patienterna som fick strukturerad hemsjukvård. I intervjuerna beskrev patienterna delaktighet som: (i) kommunikation mellan patient och vårdpersonal, som innebar att det fanns tid och utrymme för dialog och att utväxla vårdrelaterad information, (ii) tillgänglig vård, som att veta om planerade hembesök och att ha möjlighet att själv initiera hembesök, (iii) att vara aktivt involverad i sin vård, genom att utföra egenvård och att samarbeta med vårdpersonalen, (iv) att ha en förtroendefull relation till vårdpersonalen, vilket innebar att ha förtroende för såväl kompetens som att få individuellt anpassad vård, och $(v)$ att ha 
möjligheter till beslutsfattande, vilket innebar att vara involverad i beslut och diskussioner eller att överlämna besluten till vårdpersonalen.

I den tredje studien videoinspelades 19 vårdmöten mellan patienter och sjuksköterskor i samband med hembesök hos patienter som fick strukturerad hemsjukvård. Under observerade vårdmöten identifierades att (i) delaktighet $\mathrm{i}$ vårdmötet möjliggjordes genom interaktion, som innebar utbyte av vårdrelaterad information, vårdrelaterat resonemang och samarbete, (ii) delaktighet $\mathrm{i}$ vårdmötet innebar ett möjliggörande förhållningssätt vilket inkluderade att patienten uttryckte egna önskemål och visade ett aktivt intresse samt att sjuksköterskan visade engagemang och bjöd in till dialog.

I den fjärde delstudien deltog 15 partners som både besvarade frågeformulär och intervjuades. Partners skattade att de i förhållandevis stor utsträckning var nöjda med olika aspekter av delaktighet $i$ vården och att de $i$ olika utsträckning var involverade i patientens vård. I intervjuerna framkom att partners var delaktiga i patientens vård relaterat till de behov som uppkom till följd av sjukdomen och att hantera de krav som då uppstod. De beskrev också interaktion med vårdpersonalen under hembesöken och att de behövde kunskap för att greppa över patientens hälsosituation. Resultat från frågeformulär och intervjuer visade övervägande samstämmiga resultat, men gav också en ökad förståelse för partners delaktighet i samband med hemsjukvård.

Sammanfattningsvis visade avhandlingens resultat att strukturerad hemsjukvård underlättade för såväl patienters som partners delaktighet. Olika aspekter av delaktighet var associerade med bättre egenvård och patienterna skattade en förbättring av delaktighet gällande erhållen information. Patienters och partners beskrivningar av delaktighet visade på ett flertal aspekter av delaktighet. Under observerade vårdmöten identifierades hur interaktion och underlättande förhållningssätt möjliggjorde delaktighet. Partners var delaktiga i patientens vård i olika grad och de var övervägande nöjda med sin delaktighet i samband med hemsjukvård. Att ha tillgång till hemsjukvård var en trygghet för såväl patienter som partners.

För att möjliggöra delaktighet $\mathrm{i}$ vården är det viktig att utgå från personens preferenser gällande delaktighet, då detta varierar från person till person. En hög tillgänglighet i hemsjukvården har stor betydelse för upplevelse av delaktighet. Tid och utrymme för dialog behöver ges under hembesök, där 
både patienter och deras partners har utrymme och ges möjlighet att ställa frågor. Att vården organiseras utifrån kontinuitet med vårdpersonal bör eftersträvas för att förtroendefulla relationer ska ha möjlighet att utvecklas. 



\section{ACKNOWLEDGEMENTS}

I want to express my warmest and deepest gratitude to all of those who in different ways have contributed to this thesis.

In particular I wish to thank:

All patients, partners and nurses who participated in the studies. My deepest thanks to all of you.

Professor Anna Strömberg, my main supervisor. Thank you for inviting me on this journey and for generously sharing your experience and knowledge all the way through this thesis. You have always encouraged me, shown great patience and supported me. I have enjoyed working with you and getting to know you over these years. I have learned so much from you - our journey has meant a lot to me.

Professor Ewa Idvall, my co-supervisor. You have always been encouraging and positive during this thesis. You have also generously shared your knowledge and provided important input to my work. Thank you for good collaboration.

Professor Tiny Jaarsma, Associate professor Kristofer Årestedt, Professor Jan Mårtensson, and PhD Marie Louise Luttik, for your valuable contribution as co-authors of the studies in this thesis. All of you have generously shared your experience and knowledge with me and have always been encouraging. I am grateful that I had the opportunity to work together with all of you.

The management and staff at the different home-care units, who kindly gave me access to your units and showing interest in this project. My deepest thanks to Ann-Britt, AnneCharlotte, Eva, Maria, Marianne and Solveig, your contribution and enthusiasm was invaluable to me.

The management team at the Division of Nursing Science and the Nursing Programme, for encouraging me to do this thesis and supporting me with valuable time. 
Senior researchers and doctoral students from the Divisions of Nursing Science and Occupational Therapy, for valuable discussions and comments during our seminars.

My special thanks to Birgitta Salomonsson, Carina Hjelm, Carina Wennerholm, Jenny Drott, Katarina Berg, Pia Yngman-Uhlin, Sara Bergstrand and Ulla Walfridsson, for friendship and valuable support during this thesis having you around have meant a lot to me.

Sofia McGarvey for valuable help with language revision and for always being helpful and supportive whenever I have come to you.

All my colleagues at the Division of Nursing Science and the Nursing Programme for your fellowship.

Staff at the Faculty of Health Sciences library (HUB), special thanks to Jenny Betmark and Isolina Ek for valuable help with EndNote.

My parents Eivor and Stig Selander and my brother Torbjörn, you have believed in me and always encouraged me during these years. To my parentsin-law, Märtha and Eskil Näsström, for helping and supporting our family you were an invaluable safety net when I had to travel a lot.

The two most important persons in my life, my beloved son Johan - for being just you and the joy in my life, and my beloved husband Mattias, your love, never-ending support and always being there for me made this journey possible. I am so grateful for having the two of you in my life.

Financial support was granted by: The European Commission according to Grant Agreement Homecare 222954, Linköping University, The Swedish Heart and Lung Association, Medical Research Council of Southeast Sweden, and County Council Östergötland. 


\section{REFERENCES}

Adams J, Kuchibhatla M, Christopher EJ, Alexander JD, Clary GL, Cuffe MS, Califf RM, Krishnan RR, O'Connor CM \& Jiang W (2012) Association of depression and survival in patients with chronic heart failure over 12 Years. Psychosomatics 53, 339-346.

AHA (1994) The Criteria Committee of the New York Heart Association. Nomenclature and Criteria for Diagnosis of Diseases of the Heart and Great Vessels, 9th edn. Mass: Little, Brown \& Co, Boston.

Aldred H, Gott M \& Gariballa S (2005) Advanced heart failure: impact on older patients and informal carers. J Adv Nurs 49, 116-124.

Altman DG (1999) Practical statistics for medical research. Chapman \& Hall, London.

Arnetz J, Almin K, Bergström Y, Y. F \& Nilsson H (2004) Active patient involvement in the establishment of physical therapy goals: Effects on treatment outcome and quality of care. Adv Physiother 6, 50-69.

Arnetz JE, Hoglund AT, Arnetz BB \& Winblad U (2008a) Development and evaluation of a questionnaire for measuring patient views of involvement in myocardial infarction care. Eur J Cardiovasc Nurs 7, 229-238.

Arnetz JE, Winblad U, Arnetz BB \& Hoglund AT (2008b) Physicians' and nurses' perceptions of patient involvement in myocardial infarction care. Eur J Cardiovasc Nurs 7, 113-120.

Arnetz JE, Hoglund AT, Arnetz BB \& Winblad U (2008c) Staff views and behaviour regarding patient involvement in myocardial infarction care: development and evaluation of a questionnaire. Eur J Cardiovasc Nurs 7, 27-35.

Ashworth PD, Longmate MA \& Morrison P (1992) Patient participation: its meaning and significance in the context of caring. J Adv Nurs 17, 1430-1439.

Barnes S, Gott M, Payne S, Parker C, Seamark D, Gariballa S \& Small N (2006a) Prevalence of symptoms in a community-based sample of heart failure patients. J Pain Symptom Manage 32, 208-216.

Barnes S, Gott M, Payne S, Seamark D, Parker C, Gariballa S \& Small N (2006b) Communication in heart failure: perspectives from older people and primary care professionals. Health Soc Care Community 14, 482-490.

Bastiaens H, Van Royen P, Pavlic DR, Raposo V \& Baker R (2007) Older people's preferences for involvement in their own care: a qualitative study in primary health care in 11 European countries. Patient Educ Couns 68, 33-42.

Berg BL (2009) Qualitative Research Methods for the Social Sciences, 7th edn. Allynch \& Bacon, Boston.

Blue L, Lang E, McMurray JJ, Davie AP, McDonagh TA, Murdoch DR, Petrie MC, Connolly E, Norrie J, Round CE, Ford I \& Morrison CE (2001) Randomised controlled trial of specialist nurse intervention in heart failure. BMJ 323, 715-718.

Botroff J L (1993) Using videotaped recordings in qualitative research. In Critical issues Issues in Qualitatve Research Methods (Morse J M ed.). Sage, Thousand Oaks.

Boyde M, Turner C, Thompson DR \& Stewart S (2011) Educational interventions for patients with heart failure: a systematic review of randomized controlled trials. J Cardiovasc Nurs 26, E27-35. 
Brännström M, Brulin C, Norberg A, Boman K \& Strandberg G (2005) Being a palliative nurse for persons with severe congestive heart failure in advanced homecare. Eur J Cardiovasc Nurs 4, 314-323.

Brännström M, Ekman I, Norberg A, Boman K \& Strandberg G (2006) Living with severe chronic heart failure in palliative advanced home care. Eur J Cardiovasc Nurs 5, 295302.

Brooks R (1996) EuroQol: the current state of play. Health Policy 37, 53-72.

Buck HG, Kitko L \& Hupcey JE (2013) Dyadic heart failure care types: qualitative evidence for a novel typology. J Cardiovasc Nurs 28,:E37-46.

Buck HG, Harkness K, Wion R, Carroll SL, Cosman T, Kaasalainen S, Kryworuchko J, McGillion M, O'Keefe-McCarthy S, Sherifali D, Strachan PH \& Arthur HM (2015) Caregivers' contributions to heart failure self-care: A systematic review. Eur J Cardiovasc Nurs 14, 79-89.

Bui AL, Horwich TB \& Fonarow GC (2011) Epidemiology and risk profile of heart failure. Nat Rev Cardiol 8, 30-41.

Bundkirchen A \& Schwinger RHG (2004) Epidemiology and economic burden of chronic heart failure. Eur Heart J Suppl 6, D57-D60.

Burton D, Blundell N, Jones M, Fraser A \& Elwyn G (2010) Shared decision-making in cardiology: do patients want it and do doctors provide it? Patient Educ Couns 80, 173179.

Cahill J (1996) Patient participation: a concept analysis. J Adv Nurs 24, 561-571.

Cahill J (1998) Patient participation-a review of the literature. J Clin Nurs 7, 119-128.

Charlson ME, Pompei P, Ales KL \& MacKenzie CR (1987) A new method of classifying prognostic comorbidity in longitudinal studies: development and validation. J Chronic Dis 40, 373-383.

Charlton CR, Dearing KS, Berry JA \& Johnson MJ (2008) Nurse practitioners' communication styles and their impact on patient outcomes: an integrated literature review. J Am Acad Nurse Pract 20, 382-388.

Chung ML, Moser DK, Lennie TA \& Rayens MK (2009) The effects of depressive symptoms and anxiety on quality of life in patients with heart failure and their spouses: testing dyadic dynamics using Actor-Partner Interdependence Model. J Psychosom Res 67, 2935.

Clark AM, Reid ME, Morrison CE, Capewell S, Murdoch DL \& McMurray JJ (2008) The complex nature of informal care in home-based heart failure management. J Adv Nurs 61, 373-383.

Clark AM, Spaling M, Harkness K, Spiers J, Strachan PH, Thompson DR \& Currie K (2014) Determinants of effective heart failure self-care: a systematic review of patients' and caregivers' perceptions. Heart 100, 716-721.

Coons SJ, Rao S, Keininger DL \& Hays RD (2000) A comparative review of generic qualityof-life instruments. Pharmaco Economics 17, 13-35.

Cowie M, Anker SD, Cleland J, Felker GM, Filippatos G, Jaarsma T, Jourdain P, Knight E, Massie B, Ponikowski P \& López-Sendón J (2014) Improving care for patients with heart failure; Before, during and after hospitalization, Available at: http://www.oxfordhealthpolicyforum.org/AHFreport Accessed 141210.

Creswell JW \& Plano Clark VL (2011) Designing and conducting mixed methods research 2nd edition. Sage, Thousand Oaks. 
Currie K, Strachan PH, Spaling M, Harkness K, Barber D \& Clark AM (2014) The importance of interactions between patients and healthcare professionals for heart failure selfcare: A systematic review of qualitative research into patient perspectives. Eur J Cardiovasc Nurs pii: 1474515114547648.

de Groot V, Beckerman H, Lankhorst GJ \& Bouter LM (2003) How to measure comorbidity: a critical review of available methods. J Clin Epidemiol 56, 221-229.

Dekker RL (2014) Patient Perspectives About Depressive Symptoms in Heart Failure A Review of the Qualitative Literature. J Cardiovasc Nurs 29, E9-E15.

Dickson VV \& Riegel B (2009) Are we teaching what patients need to know? Building skills in heart failure self-care. Heart Lung 38, 253-261.

Dickson VV, Buck H \& Riegel B (2013) Multiple comorbid conditions challenge heart failure self-care by decreasing self-efficacy. Nurs Res 62, 2-9.

Downe-Wamboldt B (1992) Content analysis: method, applications, and issues. Health Care Women Int 13, 313-321.

Dunbar SB, Clark PC, Quinn C, Gary RA \& Kaslow NJ (2008) Family influences on heart failure self-care and outcomes. J Cardiovasc Nurs 23, 258-265.

Dunlay SM \& Roger VL (2014) Understanding the epidemic of heart failure: past, present, and future. Curr Heart Fail Rep 11, 404-415.

Eastwood JA, Moser DK, Riegel BJ, Albert NM, Pressler S, Chung ML, Dunbar S, Wu JR \& Lennie TA (2012) Commonalities and differences in correlates of depressive symptoms in men and women with heart failure. Eur J Cardiovasc Nurs 11, 356-365.

Ekdahl AW, Andersson L \& Friedrichsen M (2010) "They do what they think is the best for me." Frail elderly patients' preferences for participation in their care during hospitalization. Patient Educ Couns 80, 233-240.

Ekdahl AW, Andersson L, Wirehn AB \& Friedrichsen M (2011) Are elderly people with comorbidities involved adequately in medical decision making when hospitalised? A cross-sectional survey. BMC Geriatr 11, 46.

Ekdahl AW, Linderholm M, Hellstrom I, Andersson L \& Friedrichsen M (2012) 'Are decisions about discharge of elderly hospital patients mainly about freeing blocked beds?' A qualitative observational study. BMJ Open 2, e002027.

Eldh AC, Ehnfors M \& Ekman I (2004) The phenomena of participation and nonparticipation in health care--experiences of patients attending a nurse-led clinic for chronic heart failure. Eur J Cardiovasc Nurs 3, 239-246.

Eldh AC, Ekman I \& Ehnfors M (2006a) Conditions for patient participation and nonparticipation in health care. Nurs Ethics 13, 503-514.

Eldh AC, Ehnfors M \& Ekman I (2006b) The meaning of patient participation for patients and nurses at a nurse-led clinic for chronic heart failure. Eur J Cardiovasc Nurs 5, 45-53.

Eldh AC, Ekman I \& Ehnfors M (2010) A comparison of the concept of patient participation and patients' descriptions as related to healthcare definitions. Int J Nurs Terminol Classif 21, 21-32.

Evangelista LS \& Shinnick MA (2008) What do we know about adherence and self-care? J Cardiovasc Nurs 23, 250-257.

Falk H, Ekman I, Anderson R, Fu M \& Granger B (2013) Older patients' experiences of heart failure-an integrative literature review. J Nurs Scholarsh 45, 247-255.

Foss C (2011) Elders and patient participation revisited - a discourse analytic approach to older persons' reflections on patient participation. J Clin Nurs 20, 2014-2022. 
Frank C, Asp M \& Dahlberg K (2009) Patient participation in emergency care - a phenomenographic study based on patients' lived experience. Int Emerg Nurs 17, 1522.

Franzen-Årestedt K, Saveman BI \& Blomqvist K (2007) Predictors for health related quality of life in persons 65 years or older with chronic heart failure. Eur J Cardiovasc Nurs 6, 112-120.

Genet N, Boerma WG, Kringos DS, Bouman A, Francke AL, Fagerstrom C, Melchiorre MG, Greco C \& Deville W (2011) Home care in Europe: a systematic literature review. BMC Health Serv Res 11, 207.

Go AS, Mozaffarian D, Roger VL, Benjamin EJ, Berry JD, Blaha MJ, Dai S, Ford ES, Fox CS, Franco S, Fullerton HJ, Gillespie C, Hailpern SM, Heit JA, Howard VJ, Huffman MD, Judd SE, Kissela BM, Kittner SJ, Lackland DT, Lichtman JH, Lisabeth LD, Mackey RH, Magid DJ, Marcus GM, Marelli A, Matchar DB, McGuire DK, Mohler ER, 3rd, Moy CS, Mussolino ME, Neumar RW, Nichol G, Pandey DK, Paynter NP, Reeves MJ, Sorlie PD, Stein J, Towfighi A, Turan TN, Virani SS, Wong ND, Woo D \& Turner MB (2014) Executive summary: heart disease and stroke statistics--2014 update: a report from the American Heart Association. Circulation 129, 399-410.

Graneheim UH \& Lundman B (2004) Qualitative content analysis in nursing research: concepts, procedures and measures to achieve trustworthiness. Nurse Educ Today 24, 105-112.

Greenfield S, Kaplan SH, Ware JE, Jr., Yano EM \& Frank HJ (1988) Patients' participation in medical care: effects on blood sugar control and quality of life in diabetes. J Gen Intern Med 3, 448-457.

Grove SK, Burns N \& Gray JR (2013) The practice of nursing research. Appraisal, synthesis and generation of evidence. 7th ed. Elsevier, Saunders, St. Louis, Missouri.

Guadagnoli E \& Ward P (1998) Patient participation in decision-making. Soc Sci \& Med 47, 329-339.

Gusdal AK, Josefsson K, Adolfsson ET \& Martin L (2014) Informal Caregivers' Experiences and Needs When Caring for a Relative With Heart Failure: An Interview Study. J Cardiovasc Nurs DOI: 10.1097/JCN.0000000000000210.

Hagedorn ME \& Zahourek RP (2007) Research paradigms and methods for investigating holistic nursing concerns. Nurs Clin North Am 42, 335-353, viii.

Hammash MH, Hall LA, Lennie TA, Heo S, Chung ML, Lee KS \& Moser DK (2013) Psychometrics of the PHQ-9 as a measure of depressive symptoms in patients with heart failure. Eur J Cardiovasc Nurs 12, 446-453.

Heo S, Moser DK, Lennie TA, Zambroski CH \& Chung ML (2007) A comparison of healthrelated quality of life between older adults with heart failure and healthy older adults. Heart Lung 36, 16-24.

Hertzog MA, Pozehl B \& Duncan K (2010) Cluster analysis of symptom occurrence to identify subgroups of heart failure patients: a pilot study. J Cardiovasc Nurs 25, 273283.

Hogstel MO, Curry LC \& Walker C (2005) Caring for older adults, the benefits of informal family caregiving. J Theory Construct Test 9, 55-60.

Holmberg M, Valmari G \& Lundgren SM (2012) Patients' experiences of homecare nursing: balancing the duality between obtaining care and to maintain dignity and selfdetermination. Scand J Caring Sci 26, 705-712. 
Holzapfel N, Lowe B, Wild B, Schellberg D, Zugck C, Remppis A, Katus HA, Haass M, Rauch B, Junger J, Herzog W \& Muller-Tasch T (2009) Self-care and depression in patients with chronic heart failure. Heart Lung 38, 392-397.

Howie-Esquivel J \& Dracup K (2012) Communication with hospitalized heart failure patients. Eur J Cardiovasc Nurs 11, 216-222.

Höglund AT, Winblad U, Arnetz B \& Arnetz JE (2010) Patient participation during hospitalization for myocardial infarction: perceptions among patients and personnel. Scand J Caring Sci 24, 482-489.

Imes CC, Dougherty CM, Pyper G \& Sullivan MD (2011) Descriptive study of partners' experiences of living with severe heart failure. Heart Lung 40, 208-216.

International Council of Nurses (2012) The ICN Code of Ethics for Nurses, Geneva, Switzerland.

Jaarsma T, Strömberg A, De Geest S, Fridlund B, Heikkila J, Mårtensson J, Moons P, Scholte op Reimer W, Smith K, Stewart S \& Thompson DR (2006) Heart failure management programmes in Europe. Eur J Cardiovasc Nurs 5, 197-205.

Jaarsma T, Årestedt KF, Mårtensson J, Dracup K \& Strömberg A (2009) The European Heart Failure Self-care Behaviour scale revised into a nine-item scale (EHFScB-9) a reliable and valid international instrument. Eur J Heart Fail 11, 99-105.

Jaarsma T, Strömberg A \& Alonso A (2010a) A description of EU-criteria/components for optimal based management of heart failure patients. Available at:

http://integratedhomecare.eu/uploads/Diverse\%20uploads/D2_Homecare\%20222954. pdf

Jaarsma T, Johansson P, Ågren S \& Strömberg A (2010b) Quality of life and symptoms of depression in advanced heart failure patients and their partners. Curr Opin Support Palliat Care 4, 233-237.

Jaarsma T \& Luttik ML (2011) Home care in heart failure: towards an integrated care model. Eur J Heart Fail 13, 823-824.

Jeon YH, Kraus SG, Jowsey T \& Glasgow NJ (2010) The experience of living with chronic heart failure: a narrative review of qualitative studies. BMC Health Serv Res 10, 77.

Jewell S (1996) Elderly patients' participation in discharge decision making: 1. Br J Nurs 5, 914-916, 929-932.

Johansson P, Nieuwenhuis M, Lesman-Leegte I, van Veldhuisen DJ \& Jaarsma T (2011) Depression and the delay between symptom onset and hospitalization in heart failure patients. Eur J Heart Fail 13, 214-219.

Juenger J, Schellberg D, Kraemer S, Haunstetter A, Zugck C, Herzog W \& Haass M (2002) Health related quality of life in patients with congestive heart failure: comparison with other chronic diseases and relation to functional variables. Heart 87, 235-241.

Kang X, Li Z \& Nolan MT (2011) Informal caregivers' experiences of caring for patients with chronic heart failure: systematic review and metasynthesis of qualitative studies. $J$

Cardiovasc Nurs 26, 386-394.

Karmilovich SE (1994) Burden and stress associated with spousal caregiving for individuals with heart failure. Prog Cardiovasc Nurs 9, 33-38.

Knapp TR (1990) Treating ordinal scales as interval scales: an attempt to resolve the controversy. Nurs Res 39, 121-123.

Kroenke K, Spitzer RL \& Williams JB (2001) The PHQ-9: validity of a brief depression severity measure. J Gen Intern Med 16, 606-613. 
Kvale S \& Brinkmann S (2009) Den kvalitativa forskningsintervjun, 2a uppl. Studentlitteratur, Lund.

Lainscak M, Blue L, Clark AL, Dahlstrom U, Dickstein K, Ekman I, McDonagh T, McMurray JJ, Ryder M, Stewart S, Stromberg A \& Jaarsma T (2011) Self-care management of heart failure: practical recommendations from the Patient Care Committee of the Heart Failure Association of the European Society of Cardiology. Eur J Heart Fail 13, 115-126.

Larsson IE, Sahlsten MJ, Sjöström B, Lindencrona CS \& Plos KA (2007) Patient participation in nursing care from a patient perspective: a Grounded Theory study. Scand J Caring Sci 21, 313-320.

Larsson IE, Sahlsten MJ, Segesten K \& Plos KA (2011a) Patients' perceptions of barriers for participation in nursing care. Scand J Caring Sci 25, 575-582.

Larsson IE, Sahlsten MJ, Segesten K \& Plos KA (2011b) Patients' perceptions of nurses' behaviour that influence patient participation in nursing care: a critical incident study. Nurs Res Pract 2011, 534060.

Lee A \& Craft-Rosenberg M (2002) Ineffective family participation in professional care: a concept analysis of a proposed nursing diagnosis. Nurs Diagn 13, 5-14.

Lee CS, Moser DK, Lennie TA \& Riegel B (2011) Event-free survival in adults with heart failure who engage in self-care management. Heart Lung 40, 12-20.

Lesman-Leegte I, Jaarsma T, Coyne JC, Hillege HL, Van Veldhuisen DJ \& Sanderman R (2009) Quality of life and depressive symptoms in the elderly: a comparison between patients with heart failure and age- and gender-matched community controls. J Card Fail 15, 17-23.

Liljeroos M, Ågren S, Jaarsma T \& Strömberg A (2014) Perceived caring needs in patientpartner dyads affected by heart failure: A qualitative study. J Clin Nurs 23, 2928-2938.

Lincoln YS \& Guba EG (1985) Naturalistic Inquiry. Sage, Newbury Park, CA.

Lloyd-Jones D, Adams RJ, Brown TM, Carnethon M, Dai S, De Simone G, Ferguson TB, Ford E, Furie K, Gillespie C, Go A, Greenlund K, Haase N, Hailpern S, Ho PM, Howard V, Kissela B, Kittner S, Lackland D, Lisabeth L, Marelli A, McDermott MM, Meigs J, Mozaffarian D, Mussolino M, Nichol G, Roger VL, Rosamond W, Sacco R, Sorlie P, Thom T, Wasserthiel-Smoller S, Wong ND \& Wylie-Rosett J (2010) Heart disease and stroke statistics--2010 update: a report from the American Heart Association.

Circulation 121, e46-e215.

Loh A, Leonhart R, Wills CE, Simon D \& Harter M (2007) The impact of patient participation on adherence and clinical outcome in primary care of depression. Patient Educ Couns 65, 69-78.

Luttik ML, Jaarsma T, Veeger NJ \& van Veldhuisen DJ (2005) For better and for worse: Quality of life impaired in HF patients as well as in their partners. Eur J Cardiovasc Nurs 4, 11-14.

Luttik ML, Blaauwbroek A, Dijker A \& Jaarsma T (2007) Living with heart failure: partner perspectives. J Cardiovasc Nurs 22, 131-137.

Luttik ML, Jaarsma T, Tijssen JG, van Veldhuisen DJ \& Sanderman R (2008) The objective burden in partners of heart failure patients; development and initial validation of the Dutch Objective Burden Inventory. Eur J Cardiovasc Nurs 7, 3-9.

Luttik ML, Jaarsma T, Lesman I, Sanderman R \& Hagedoorn M (2009) Quality of life in partners of people with congestive heart failure: gender and involvement in care. $J$ Adv Nurs 65, 1442-1451. 
Lyttle DJ \& Ryan A (2010) Factors influencing older patients' participation in care: a review of the literature. Int J Older People Nurs 5, 274-282.

McAlister FA, Stewart S, Ferrua S \& McMurray JJ (2004) Multidisciplinary strategies for the management of heart failure patients at high risk for admission: a systematic review of randomized trials. J Am Coll Cardiol 44, 810-819.

McCormack B \& McCance TV (2006) Development of a framework for person-centred nursing. J Adv Nurs 56, 472-479.

McMurray JJ, Adamopoulos S, Anker SD, Auricchio A, Bohm M, Dickstein K, Falk V, Filippatos G, Fonseca C, Gomez-Sanchez MA, Jaarsma T, Kober L, Lip GY, Maggioni AP, Parkhomenko A, Pieske BM, Popescu BA, Ronnevik PK, Rutten FH, Schwitter J, Seferovic P, Stepinska J, Trindade PT, Voors AA, Zannad F \& Zeiher A (2012) ESC Guidelines for the diagnosis and treatment of acute and chronic heart failure 2012: The Task Force for the Diagnosis and Treatment of Acute and Chronic Heart Failure 2012 of the European Society of Cardiology. Developed in collaboration with the Heart Failure Association (HFA) of the ESC. Eur Heart J 33, 1787-1847.

Millard L, Hallett C \& Luker K (2006): Nurse-patient interaction and decision-making in care: patient involvement in community nursing. J Adv Nurs 55, 142-150.

Morcillo C, Valderas JM, Aguado O, Delas J, Sort D, Pujadas R \& Rosell F (2005) [Evaluation of a home-based intervention in heart failure patients. Results of a randomized study]. Rev Esp Cardiol 58, 618-625.

Mosterd A \& Hoes AW (2007) Clinical epidemiology of heart failure. Heart 93, 1137-1146.

Moumjid N, Christine D-B, Denois-Regnier V, Roux P \& Soum-Pouyalet F (2011) Shared decision making in the physician-patient encounter in France: a general overview in 2011. Z Evid Fortbild Qual Gesundhwes 105, 259-262.

Mårtensson J, Dracup K \& Fridlund B (2001) Decisive situations influencing spouses' support of patients with heart failure: a critical incident technique analysis. Heart Lung 30, 341350.

Neumann T, Biermann J, Erbel R, Neumann A, Wasem J, Ertl G \& Dietz R (2009) Heart failure: the commonest reason for hospital admission in Germany: medical and economic perspectives. Dtsch Arztebl Int 106, 269-275.

Page RL \& Lindenfeld J (2012) The comorbidity conundrum: a focus on the role of noncardiovascular chronic conditions in the heart failure patient. Curr Cardiol Rep 14, 276-284.

Patel H, Shafazand M, Ekman I, Hojgard S, Swedberg K \& Schaufelberger M (2008) Home care as an option in worsening chronic heart failure -- a pilot study to evaluate feasibility, quality adjusted life years and cost-effectiveness. Eur J Heart Fail 10, 675681.

Patton MQ (2002) Qualitative research and evaluation methods, 3rd edn. Sage Publications, Thousand Oaks.

Peterson JC, Paget SA, Lachs MS, Reid MC \& Charlson ME (2012) The risk of comorbidity. Ann Rheum Dis 71, 635-637.

Piamjariyakul U, Smith CE, Werkowitch M \& Elyachar A (2012) Part I: heart failure home management: patients, multidisciplinary health care professionals and family caregivers' perspectives. Appl Nurs Res 25, 239-245.

Polit DF \& Beck CT (2012) Nursing Research, Generating and Assessing Evidence for Nursing Practice, 9th edn. Lippincott Williams \& Wilkins, Philadelphia. 
Ponikowski P, Anker SD, AlHabib KF, Cowie MR, Force TL, Hu S, Jaarsma T, Krum H, Rastogi V, Rohde LE, Samal UC, Shimokawa H, Siswanto B, Sliwa K \& G. F (2014) Heart failure Preventing disease and death worldwide, Available at: http://www.escardio.org/communities/HFA/Documents/whfa-whitepaper.pdf Accessed 141210.

Riegel B, Vaughan Dickson V, Goldberg LR \& Deatrick JA (2007) Factors associated with the development of expertise in heart failure self-care. Nurs Res 56, 235-243.

Riegel B \& Dickson VV (2008) A situation-specific theory of heart failure self-care. J Cardiovasc Nurs 23, 190-196.

Riegel B, Jaarsma T \& Strömberg A (2012) A middle-range theory of self-care of chronic illness. ANS Adv Nurs Sci 35, 194-204.

Rodriguez KL, Appelt CJ, Switzer GE, Sonel AF \& Arnold RM (2008) Veterans' decisionmaking preferences and perceived involvement in care for chronic heart failure. Heart Lung 37, 440-448.

Rosland AM, Heisler M, Choi HJ, Silveira MJ \& Piette JD (2010) Family influences on selfmanagement among functionally independent adults with diabetes or heart failure: do family members hinder as much as they help? Chronic Illn 6, 22-33.

Rutledge T, Reis VA, Linke SE, Greenberg BH \& Mills PJ (2006) Depression in heart failure a meta-analytic review of prevalence, intervention effects, and associations with clinical outcomes. J Am Coll Cardiol 48, 1527-1537.

Sahlsten MJ, Larsson IE, Plos KA \& Lindencrona CS (2005) Hindrance for patient participation in nursing care. Scand J Caring Sci 19, 223-229.

Sahlsten MJ, Larsson IE, Sjostrom B, Lindencrona CS \& Plos KA (2007) Patient participation in nursing care: towards a concept clarification from a nurse perspective. J Clin Nurs 16, 630-637.

Sahlsten MJ, Larsson IE, Sjostrom B \& Plos KA (2008) An analysis of the concept of patient participation. Nurs Forum 43, 2-11.

Sahlsten MJ, Larsson IE, Sjostrom B \& Plos KA (2009) Nurse strategies for optimising patient participation in nursing care. Scand J Caring Sci 23, 490-497.

Sainio C, Eriksson E \& Lauri S (2001) Patient participation in decision making about care. Cancer Nurs 24, 172-179.

Saunders MM (2008) Factors associated with caregiver burden in heart failure family caregivers. West J Nurs Res 30, 943-959.

Say R, Murtagh M \& Thomson R (2006) Patients' preference for involvement in medical decision making: a narrative review. Patient Educ Couns 60, 102-114.

Schoot T, Proot I, Meulen RT \& de Witte L (2005) Actual interaction and client centeredness in home care. Clin Nurs Res 14, 370-393.

Sebern M \& Riegel B (2009) Contributions of supportive relationships to heart failure selfcare. Eur J Cardiovasc Nurs 8, 97-104.

Seferovic PM, Stoerk S, Filippatos G, Mareev V, Kavoliuniene A, Ristic AD, Ponikowski P, McMurray J, Maggioni A, Ruschitzka F, van Veldhuisen DJ, Coats A, Piepoli M, McDonagh T, Riley J, Hoes A, Pieske B, Dobric M, Papp Z, Mebazaa A, Parissis J, Ben Gal T, Vinereanu D, Brito D, Altenberger J, Gatzov P, Milinkovic I, Hradec J, Trochu JN, Amir O, Moura B, Lainscak M, Comin J, Wikstrom G \& Anker S (2013) Organization of heart failure management in European Society of Cardiology member countries: survey of the Heart Failure Association of the European Society of 
Cardiology in collaboration with the Heart Failure National Societies/Working Groups. Eur J Heart Fail 15, 947-959.

Skär L \& Söderberg S (2011) The use of information and communication technology to meet chronically ill patients' needs when living at home. Open Nurs J 5, 74-78.

Socialdepartementet (1982) Hälso- och sjukvårdslag 1982:763, Available at: http://www.notisum.se/rnp/sls/lag/19820763.htm Accessed 141210.

Socialdepartementet (2014) Patientlag 2014:821, Available at:http://www.notisum.se/rnp/sls/sfs/20140821.pdf Accessed 150115.

Socialstyrelsen (2008) Hemsjukvård i förändring, En kartläggning av hemsjukvården i Sverige och förslag till indikationer, Available at: www.socialstyrelsen.se Accessed 141210.

Socialstyrelsen (2009) Bedömning av om en hälso- och sjukvårdsåtgärd kan utföras som egenvård, SOSFS 2009:6, Available at: http://www.socialstyrelsen.se/sosfs/2009-6 Accessed 141210.

Socialstyrelsen (2012) Din skyldighet att informera och göra patienten delaktig Handbok för vårdgivare, chefer och personal, Available at: www.socialstyrelsen.se Accessed 141210.

Socialstyrelsen (2014) Hemvård, En kartläggning av översikter, Available at: www.socialstyrelsen.se Accessed 150125.

Spitzer RL, Kroenke K \& Williams JB (1999) Validation and utility of a self-report version of PRIME-MD: the PHQ primary care study. Primary Care Evaluation of Mental Disorders. Patient Health Questionnaire. JAMA 282, 1737-1744.

Stewart S \& Horowitz JD (2002) Home-based intervention in congestive heart failure: longterm implications on readmission and survival. Circulation 105, 2861-2866.

Stewart S, Carrington MJ, Marwick TH, Davidson PM, Macdonald P, Horowitz JD, Krum H, Newton PJ, Reid C, Chan YK \& Scuffham PA (2012) Impact of home versus clinicbased management of chronic heart failure: the WHICH? (Which Heart Failure Intervention Is Most Cost-Effective \& Consumer Friendly in Reducing Hospital Care) multicenter, randomized trial. J Am Coll Cardiol 60, 1239-1248.

Streiner D \& Norman G (2003) Health measurement scales a practical guide to development and use, 3rd edn. Oxford University Press, Oxford.

Strömberg A (2005) The crucial role of patient education in heart failure. Eur J Heart Fail 7, 363-369.

Strömberg A (2013) The situation of caregivers in heart failure and their role in improving patient outcomes. Curr Heart Fail Rep 10, 270-275.

Tarricone R \& Tsouros A (2008) Home care in Europe. World Health Organization, Regional Office for Europe, Copenhagen.

The EuroQol Group (1990) EuroQol--a new facility for the measurement of health-related quality of life. Health Policy 16, 199-208.

Thomas SA, Chapa DW, Friedmann E, Durden C, Ross A, Lee MC \& Lee HJ (2008)

Depression in patients with heart failure: prevalence, pathophysiological mechanisms, and treatment. Crit Care Nurse 28, 40-55.

Thompson AG (2007) The meaning of patient involvement and participation in health care consultations: a taxonomy. Soc Sci Med 64, 1297-1310.

Tritter JQ (2009) Revolution or evolution: the challenges of conceptualizing patient and public involvement in a consumerist world. Health Expect 12, 275-287. 
Tritter JQ (2011) Public and patient participation in health care and health policy in the United Kingdom. Health Expect 14, 220-223.

Tutton EM (2005) Patient participation on a ward for frail older people. J Adv Nurs 50, 143152.

van der Wal MH, Jaarsma T, Moser DK \& van Veldhuisen DJ (2005) Development and testing of the Dutch Heart Failure Knowledge Scale. Eur J Cardiovasc Nurs 4, 273-277.

Wellard S, Lillibridge J, Beanland C \& Lewis M (2003) Consumer participation in acute care settings: an Australian experience. Int J Nurs Pract 9, 255-260.

Vellone E, Chung ML, Cocchieri A, Rocco G, Alvaro R \& Riegel B (2014) Effects of self-care on quality of life in adults with heart failure and their spousal caregivers: testing dyadic dynamics using the actor-partner interdependence model. J Fam Nurs 20, 120141.

Welstand J, Carson A \& Rutherford P (2009) Living with heart failure: an integrative review. Int J Nurs Stud 46, 1374-1385.

Verho H \& Arnetz JE (2003) Validation and application of an instrument for measuring patient relatives' perception of quality of geriatric care. Int J Qual Health Care 15, 197206.

Whittingham K, Barnes S \& Gardiner C (2013) Tools to measure quality of life and carer burden in informal carers of heart failure patients: a narrative review. Palliat Med 27, 596-607.

Whitty JA, Carrington MJ, Stewart S, Holliday J, Marwick TH \& Scuffham PA (2012) Patient preferences for the delivery of disease management in chronic heart failure: a qualitative study. J Cardiovasc Nurs 27, 201-207.

Wild D, Grove A, Martin M, Eremenco S, McElroy S, Verjee-Lorenz A \& Erikson P (2005) Principles of Good Practice for the Translation and Cultural Adaptation Process for Patient-Reported Outcomes (PRO) Measures: report of the ISPOR Task Force for Translation and Cultural Adaptation. Value Health 8, 94-104.

Wingham J, Harding G, Britten N \& Dalal H (2014) Heart failure patients' attitudes, beliefs, expectations and experiences of self-management strategies: A qualitative synthesis. Chronic Illn 10, 135-54

Wong CY, Chaudhry SI, Desai MM \& Krumholz HM (2011) Trends in comorbidity, disability, and polypharmacy in heart failure. Am J Med 124, 136-143.

WHO, World Health Organization (1994) A Declaration on the Promotion of Patients' Rights in Europe, Amsterdam: WHO Regional Office for Europe.

WHO, World Health Organization (2001) International Classification of Functioning, Disability and Health (ICF) 2001.Geveva, Switzerland.

WHO, World Health Organization (2013) Health 2020: a European policy framework supporting action across government and society for health and well-being. Available at: http://www.euro.who.int/_data/assets/pdf_file/0009/169803/RC62wd09Eng.pdf?ua=1 Accessed 141210. World Medical Association (2013)

World Medical Association (2013) World Medical Association Declaration of Helsinki: ethical principles for medical research involving human subjects. JAMA 310, 21912194.

Yu DS, Thompson DR \& Lee DT (2006) Disease management programmes for older people with heart failure: crucial characteristics which improve post-discharge outcomes. Eur Heart J 27, 596-612. 
Zambroski CH, Moser DK, Bhat G \& Ziegler C (2005) Impact of symptom prevalence and symptom burden on quality of life in patients with heart failure. Eur J Cardiovasc Nurs 4, 198-206.

Zarrinkoub R, Wettermark B, Wandell P, Mejhert M, Szulkin R, Ljunggren G \& Kahan T (2013) The epidemiology of heart failure, based on data for 2.1 million inhabitants in Sweden. Eur J Heart Fail 15, 995-1002.

Ågren S, Evangelista L \& Strömberg A (2010) Do partners of patients with chronic heart failure experience caregiver burden? Eur J Cardiovasc Nurs 9, 254-262.

Ågren S, Evangelista L, Davidson T \& Strömberg A (2011) The influence of chronic heart failure in patient-partner dyads--a comparative study addressing issues of healthrelated quality of life. J Cardiovasc Nurs 26, 65-73.

Årestedt L, Persson C \& Benzein E (2014) Living as a family in the midst of chronic illness. Scand J Caring Sci 28, 29-37.

Öhman M \& Söderberg S (2004) District nursing--sharing an understanding by being present. Experiences of encounters with people with serious chronic illness and their close relatives in their homes. J Clin Nurs 13, 858-866. 



\section{Papers}

The articles associated with this thesis have been removed for copyright reasons. For more details about these see:

http://urn.kb.se/resolve?urn=urn:nbn:se:liu:diva-117095 